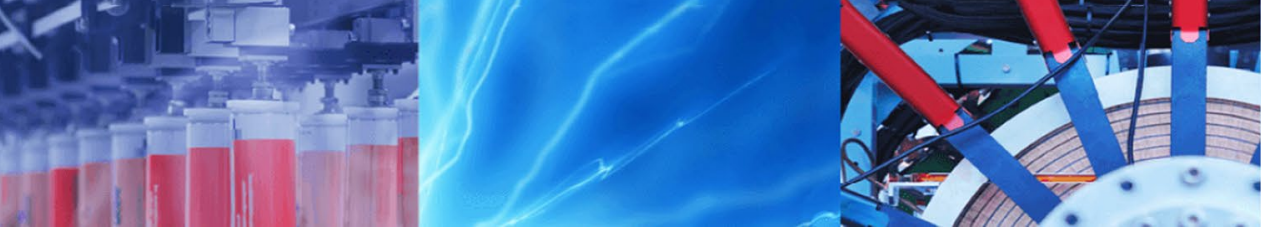

Research Article

\title{
Models for kinetic energy and momentum correction coefficients for non-prismatic compound channels using regression and gene expression programming
}

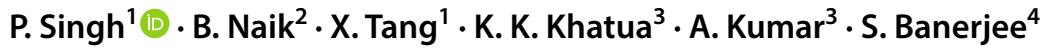

(c) Springer Nature Switzerland AG 2019

\begin{abstract}
This paper studies the effect of different independent variables related to the characteristics of the compound channels on the kinetic energy and momentum correction coefficients (termed as $\alpha$ and $\beta$, respectively) of non-prismatic compound channels. A series of experiments were carried out in a converging compound channel with three converging angles, six width ratios, six relative depths and three relative distances. Meanwhile, flow data sets from three different authors were used for diverging compound channels, which include simple rectangular and trapezoidal cross sections. In the present study, conventional multivariable regression technique and gene expression programming were used for developing different models for calculating kinetic energy and momentum correction coefficients for converging and diverging compound channels, respectively. The independent variables used in the curve fitting process were also tested for their accountability and influence on the proposed models. The developed models were finally established with the validation data set and a natural river system.
\end{abstract}

Keywords Kinetic energy correction coefficient - Momentum correction coefficient · Converging and diverging compound channel $\cdot$ Multilinear regression · GEP

\section{Introduction}

Generally, natural compound rivers have varying floodplains along their flow direction, so they are called as non-prismatic compound rivers. As natural rivers are nonprismatic, the flow often changes from uniform to nonuniform. Flow modelling in the non-prismatic compound channels becomes considerably more complex since flow gets intensified over the interfacial area of two stages with complicated structures, differential velocities, mixing layer and secondary currents. Furthermore, in converging and diverging channel flow, normally the velocity distributions are not uniform over the cross section; hence, the velocity head and the momentum flux are generally greater than the values computed using the average velocity. These values may be corrected by using the so-called energy and momentum correction coefficients, which are always slightly greater than one [1,2]. Momentum and kinetic energy principles are very often used for solving hydraulic problems to attain closure values for different hydraulic parameters [3].

However, in view of wide variations in velocity distributions reported in the literature, it in turn has been known that the variation is influenced by many factors, e.g. crosssectional shape and complexity, alignment, depth of flow, channel slope and roughness. It is really important to

P. Singh, p.singh@xjtlu.edu.cn; B. Naik, banditanaik1982@gmail.com; X.Tang, Xiao.Tang@xjtlu.edu.cn; K. K. Khatua, kkkhatua@yahoo.com; A. Kumar, arunkumar5726@gmail.com; S. Banerjee, sumit.banerjee51@gmail.com|'Department of Civil Engineering, Xi'an Jiaotong-Liverpool University, Suzhou, China. ${ }^{2}$ Department of Civil Engineering, BPUT College,

Rourkela, India. ${ }^{3}$ Department of Civil Engineering, National Institute of Technology Rourkela, Rourkela, India. ${ }^{4}$ Department of Civil Engineering, B. A. College of Engineering and Technology, Jamshedpur, India. 
determine both coefficients ( $\alpha$ and $\beta$ ) with sufficient accuracy since ignoring the effect of such variations often leads to considerable errors in stage discharge prediction, afflux studies and other related analyses for both natural and artificial channels.

Therefore, a reliable modelling of $a$ and $\beta$ correction coefficients is required to identify flooded areas, which will be helpful for flood mitigation and risk management study. To understand the effect of contraction and expansion of floodplain width on $a$ and $\beta$ correction coefficients in non-prismatic channels, we need to analyse the dependency of different geometrical and hydraulic parameters on such correction factors. In the present study, based on the experimental data from the National Institute of Technology (Rourkela) [4-7], a reliable mathematical model has been attempted to develop for predicting $a$ and $\beta$ correction coefficients for non-prismatic compound channels with different converging and diverging angles. There were many techniques for fitting the curve, among which the conventional multilinear regression (MLR) technique and new gene progression programming (GEP) were used for the nonlinear model development in this study. The obtained results have been corroborated with the experimental data sets and natural river data.

\section{Theory and background}

The velocity distribution in non-prismatic compound channel is found to be non-uniform [8-12]; correction factors then become very vital in the energy and momentum equations. Therefore, the actual velocity component has to be expressed as $a$ times the velocity head component. By definition, the kinetic energy correction coefficient $a$ is described by Eq. (1):

$\alpha=\frac{1}{A U^{3}} \int_{A} u^{3} \mathrm{~d} A$

where $u$ is the point velocity at each point in the cross section, $U$ is the cross-sectional mean velocity, $A$ is the flow area and $\mathrm{d} A$ is the differential area of the whole flow area.

Similarly, in applying the momentum equation to openchannel flows with simple or compound cross sections, the actual momentum flux of an incompressible fluid passing a cross section is given by Eq. (2):

$\int_{A} \rho u^{2} \mathrm{~d} A=\rho \beta U^{2} A$

where $\rho$ is the density of the fluid. From Eq. (2), the momentum correction coefficient, $\beta$, can then be presented as Eq. (3):

SN Applied Sciences

A SPRINGER NATURE journal
$\beta=\frac{1}{A U^{2}} \int_{A} u^{2} \mathrm{~d} A$.

Typically, the values of $a$ and $\beta$ for various open-channel cross sections may be determined from Eqs. (1) and (3) by either graphical integration or numerical methods based on the measured velocity distributions.

In this study, numerical integration was used for calculating $\alpha$ and $\beta$ correction coefficients for non-prismatic compound cross sections. The cross-sectional area $(A)$ of a channel was divided into $(N)$ number of elementary areas. For each elementary area $\left(\Delta \mathrm{A}_{i}\right)$, the corresponding average velocity $\left(u_{i}\right)$ was determined from the measured velocities. The cross-sectional average velocity $(U)$ and the correction coefficients ( $\alpha$ and $\beta$ ) were calculated using Eqs. (4)-(6):

$U=\frac{\sum_{i=1}^{N} u_{i} \Delta A_{i}}{A}$

$\alpha=\frac{\sum_{i=1}^{N} u_{i}^{3} \Delta A_{i}}{U^{3} A}$

$\beta=\frac{\sum_{i=1}^{N} u_{i}^{2} \Delta A_{i}}{U^{2} A}$.

Many researchers (e.g. [13-20]) have investigated different hydraulic parameters including $a$ and $\beta$ coefficients, which are also called Coriolis and Boussinesq coefficients, respectively, for prismatic and non-prismatic channels. The significant results obtained by these researchers have prolifically affected the studies of velocity distribution over the channel flow. Table 1 summarizes $a$ and $\beta$ values studied by various researchers in detail with their key results.

The main purpose of this study is to produce a mathematical equation for the non-prismatic channels using regression analysis. All the previous work was only carried out for the smooth or rough prismatic channels. However, the effect of varying floodplains with changing bed and flow characteristic on the correction coefficients $a$ and $\beta$ is much significant, which is missing in the past literature. Thus, new models are required to establish for the non-prismatic compound section to identify the effects of the varying characteristics of bed and flow on $\alpha$ and $\beta$ model. In addition, application and corroboration of $\alpha$ and $\beta$ equation are also carried out for non-prismatic compound cross sections in natural rivers to show effectivity of the proposed equations. 
Table 1 Average values of $a$ and $\beta$ correction coefficients by various researchers

\begin{tabular}{|c|c|c|c|}
\hline Author & Channel shape & Vegetation & Key results \\
\hline Kolupaila [21] & Over-flooded rivers & $\mathrm{N} / \mathrm{A}$ & $\begin{array}{l}\text { Average values of } a \text { and } \beta \text { were recommended as } \\
1.75 \text { and } 1.25 \text {, respectively }\end{array}$ \\
\hline Blalock and Sturm [22] & Simple channel & $\mathrm{N} / \mathrm{A}$ & $\begin{array}{l}\text { Average values of } a \text { and } \beta \text { were recommended as } \\
1.06 \text { and } 1.02\end{array}$ \\
\hline Li and Hager [15] & N/A & N/A & $\begin{array}{l}\text { Values of } a \text { and } \beta \text { depend significantly on the Man- } \\
\text { ning roughness coefficient }\end{array}$ \\
\hline Al Khatib and Gogus [2] & Symmetric compound flume & Non-vegetated & $\begin{array}{l}\text { Values of } a \text { and } \beta \text { do not significantly vary with } \\
\text { increasing main channel height }\end{array}$ \\
\hline Seckin et al. [3] & Symmetric compound channel & Non-vegetated average & $\begin{array}{l}\text { Non-vegetated average values of } a \text { and } \beta \text { were } \\
\text { obtained at } 1.094 \text { and } 1.034 \text {, respectively }\end{array}$ \\
\hline Basak and Alauddin [23] & Simple converging channel & Non-vegetated & $\begin{array}{l}\text { Average values of } a \text { at inlet and outlet found to be } \\
1.015 \text { and } 1.39\end{array}$ \\
\hline Keshavarzi et al. [24] & Symmetric compound channel & Non-vegetated & $\begin{array}{l}\text { Values of } a \text { and } \beta \text { decreased significantly with the } \\
\text { installation of the submerged vane inside the main } \\
\text { channel }\end{array}$ \\
\hline Mohanty et al. [25] & Compound channel & Non-vegetated & $\begin{array}{l}\text { Floodplain width strongly affects the values of } a \text { and } \\
\beta\end{array}$ \\
\hline Luo [26] & Symmetric compound channel & Non-vegetated & $\begin{array}{l}\text { A series of equations was presented for the determi- } \\
\text { nation of } \alpha \text { and } \beta\end{array}$ \\
\hline Al-Khatib [27] & Asymmetric compound flume & Non-vegetated & $\begin{array}{l}\text { Average values of } a \text { and } \beta \text { were found to be } 1.15 \text { and } \\
1.12\end{array}$ \\
\hline Kubrak et al. [28] & Simple rectangular channel & Partly vegetated & $\begin{array}{l}\text { Values of } \alpha \text { and } \beta \text { can be as high as } 2.8 \text { and } 1.5 \text {, } \\
\text { respectively }\end{array}$ \\
\hline Parsaie and Haghiabi [29] & Symmetric compound channel & Non-vegetated & $\begin{array}{l}\text { Values of } \alpha \text { and } \beta \text { can be as high as } 2.2 \text { and 1.4, } \\
\text { respectively }\end{array}$ \\
\hline Hamidifar et al. [30] & Asymmetric compound channel & Non-vegetated & $\begin{array}{l}\text { Average values of } a \text { and } \beta \text { were found to be } 1.28 \text { and } \\
1.10\end{array}$ \\
\hline
\end{tabular}

\section{Experimental set-up}

This paper includes two parts of study for correction coefficients $\alpha$ and $\beta$ of compound channel with converging and diverging floodplains. The first part includes the modelling of converging compound channels, which has been undertaken based on the experimental data obtained at the Hydraulics and Fluid mechanics Laboratory of Civil Engineering Department, NIT, Rourkela, India. The second part is the modelling of diverging compound channels, which has been carried out based on the data sets from other authors in the literature.

\subsection{Channel specifications}

The first part includes experimental results, which were performed on a fabricated concrete flume of $15 \mathrm{~m}$ long, $0.90 \mathrm{~m}$ wide, $0.10 \mathrm{~m}$ deep, with an average bottom slope of 0.0011 (Fig. 1). Three sets of converging compound channels with varying cross sections were built inside the concrete flume with perspex sheet. The width ratio $(\sigma)$ of the prismatic part of the channel was 1.8 , and the aspect ratio $(\delta)$ of the main channel was 5 . Figure 1 also shows the longitudinal and cross-sectional dimensions of the non-prismatic compound channels. Keeping the geometry constant, the converging angles of the channels were varied as $12.38^{\circ}, 9^{\circ}$ and $5^{\circ}$, respectively. These arrangements were used to study the effect of converging floodplain angles on water surface profile prediction of converging compound channels. The converging length of the channels was found to be $0.84,1.26$ and $2.28 \mathrm{~m}$, respectively. The roughness of the floodplain and main channel was maintained the same, and the Manning's $n$ was determined as 0.011 from the experimental runs. Water was supplied to the flume from an underground sump via an overhead tank by a series of centrifugal pumps ( $15 \mathrm{hp}$ capacity each) and then recirculated to the sump after flowing through the converging compound channels. A downstream volumetric tank fitted with closure valves is for measuring the actual discharge flowing through the channel. An adjustable vertical gate along with flow straighteners was provided in the upstream section, which is sufficiently ahead of the head gate to reduce turbulence and velocity of approach. A movable bridge was provided across the flume for both spanwise and streamwise movements of the instrument over the channel area, so that each location on the floodplain of the converging compound channel could be accessed for taking measurements. Water depths were measured directly with a point gauge located on an instrument carriage. The flow depth measurements were taken along the centre of the flume at an interval of $0.5 \mathrm{~m}$ in 
Fig. 1 a Plan view of different test reaches with cross-sectional dimensions of nonprismatic compound channel and $\mathbf{b}$ characteristic variables of converging channels (a)

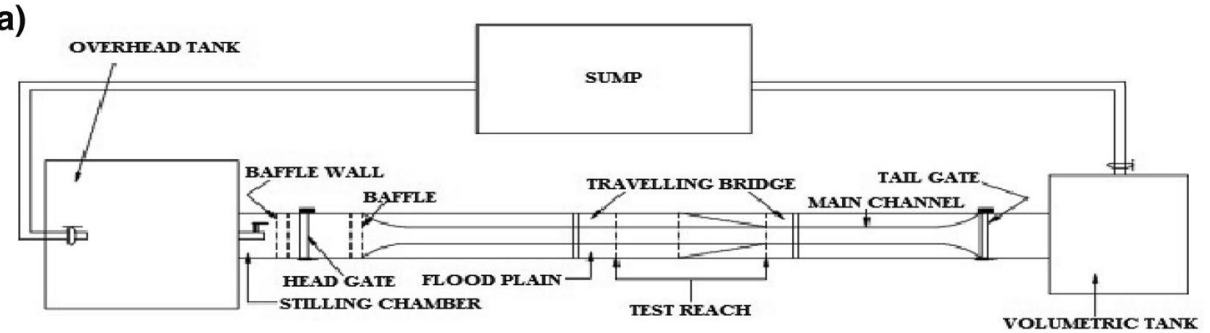

(b)

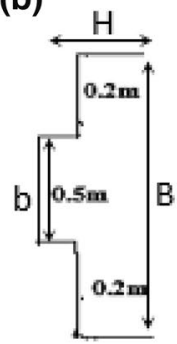

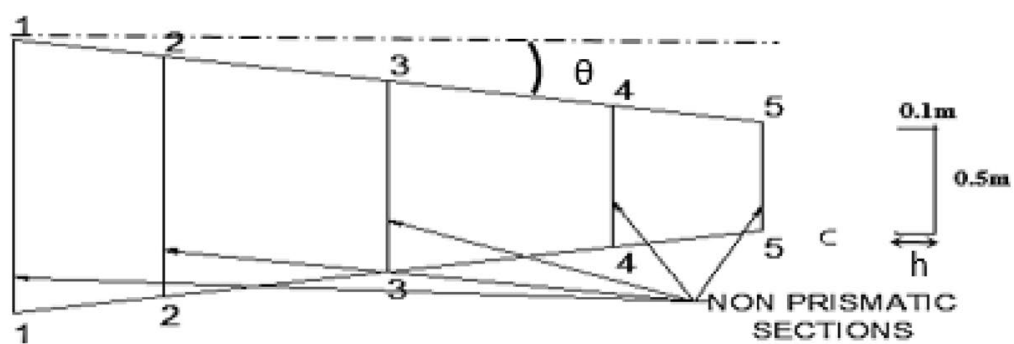

both upstream and downstream prismatic parts of the flume and at every $0.1 \mathrm{~m}$ in converging part of the flume. Figure 2 shows the non-prismatic compound channel with travelling bridges and flow measurement instruments.

Similar type of experiments was conducted by Rezaei [6]. In total, three sets of experiments were performed in his non-prismatic compound channels with convergence angles $\theta=1.91^{\circ}, 3.81^{\circ}$ and $11.31^{\circ}$. Table 2 shows the details of geometrical parameters of experimental channels from NIT, Rourkela, India.

\subsection{Velocity measurements}

A series of micro-pitot tubes of $4.77 \mathrm{~mm}$ external diameter in conjunction with a suitable vertical manometer and a 16-MHz micro-ADV (acoustic Doppler velocity meter) were used to measure longitudinal velocities. Based on acoustic frequency of instruments used, the sampling volume and sampling rate of the ADV field processing were $0.09 \mathrm{cc}$ and $0.1-50 \mathrm{~Hz}$, respectively. The acoustic instrument used for the study has the resolution of $0.01 \mathrm{~cm} / \mathrm{s}$ and accuracy of $1 \%$ of measured velocity, i.e. $\pm 0.25 \mathrm{~cm} / \mathrm{s}$. The number of velocity measurement points varied in different sets of angle $\theta$, depth of flow $H$ and total width of channel $B$. However, the vertical spacing of velocity measurement point was kept $0.2(H-h)$, while the horizontal spacing was around $0.2 \mathrm{H}$. The velocity was recorded at each point for $60 \mathrm{~s}$ at $50 \mathrm{~Hz}$. All velocities were time-averaged for each point to integrate them over Eqs. (5) and (6).

The second part of study includes collection of experimental data sets from different researchers with the extensive literature on the analysis of diverging channels. Table 3 summarizes the data sets collected from various references, such as $[4,5,7]$.
Fig. 2 Non-prismatic compound channel with travelling bridges and flow measurement instruments

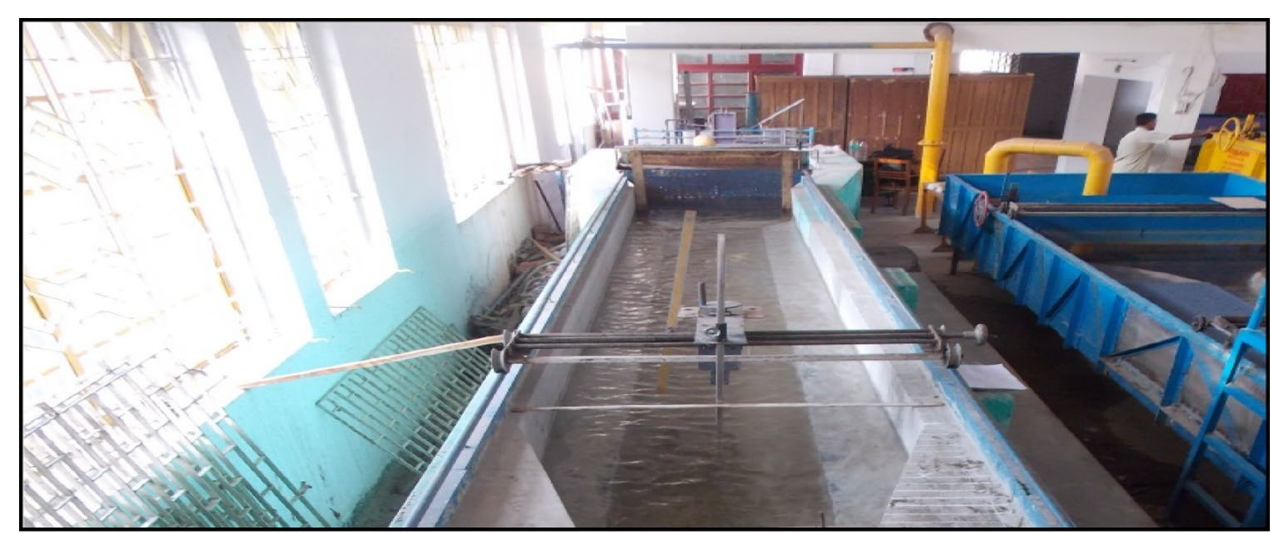


Table 2 Details of geometrical parameters of the experimental channels

\begin{tabular}{lll}
\hline No. & Description & Converging compound channel \\
\hline 1 & Geometry of main channel & Rectangular \\
2 & Geometry of floodplain & Converging \\
3 & Main channel width (b) & $0.5 \mathrm{~m}$ \\
4 & Bankfull depth of main channel & $0.1 \mathrm{~m}$ \\
5 & Top width of compound channel $\left(B_{1}\right)$ & Before convergence $0.9 \mathrm{~m}$ \\
6 & Top width of compound channel $\left(B_{2}\right)$ & After convergence $0.5 \mathrm{~m}$ \\
7 & Converging length of the channels $(L)$ & $0.84 \mathrm{~m}, 1.26,2.26 \mathrm{~m}$ \\
8 & Slope of the channel $(S)$ & 0.0011 \\
9 & Angle of convergence of floodplain $(\theta)$ & $12.38,9.0,5.0$ \\
10 & Position of experimental section 1 & Start of the converging part \\
11 & Position of experimental section 2 & $10 \mathrm{~cm}$ away from the section 1 \\
12 & Position of experimental section 3 & Middle of the converging part \\
13 & Position of experimental section 4 & $10 \mathrm{~cm}$ before the section 5 \\
14 & Position of experimental section 5 & End of the converging part \\
\hline
\end{tabular}

Table 3 Details of hydraulic parameters for all data collected from different authors

\begin{tabular}{|c|c|c|c|c|c|c|c|c|c|}
\hline \multirow[t]{2}{*}{ No. } & \multirow[t]{2}{*}{ Author } & \multirow[t]{2}{*}{ Channel shape } & \multirow[t]{2}{*}{$\begin{array}{l}\text { Discharge }(q) \\
\mathrm{m}^{3} / \mathrm{s}\end{array}$} & \multirow[t]{2}{*}{$\begin{array}{l}\text { Diverge angle } \\
\left(\Theta^{\circ}\right)\end{array}$} & \multirow[t]{2}{*}{$\begin{array}{l}\text { Width ratio } \\
(B / b)\end{array}$} & \multirow[t]{2}{*}{$\begin{array}{l}\text { Reynolds num- } \\
\text { ber }(R e)\end{array}$} & \multirow[t]{2}{*}{$\begin{array}{l}\text { Froude num- } \\
\text { ber }(F r)\end{array}$} & \multicolumn{2}{|c|}{$\begin{array}{l}\text { Average } \\
\text { value }\end{array}$} \\
\hline & & & & & & & & $a$ & $\beta$ \\
\hline 1 & $\begin{array}{l}\text { Alauddin and } \\
\text { Basak [5] }\end{array}$ & $\begin{array}{l}\text { Simple diverg- } \\
\text { ing channel }\end{array}$ & 0.0015 & 8.13 & 2.66 & $\begin{array}{l}20,985- \\
127,556\end{array}$ & $0.19-0.47$ & 1.104 & 1.039 \\
\hline 2 & Adel et al. [7] & $\begin{array}{l}\text { Simple rec- } \\
\text { tangular to } \\
\text { trapezoidal } \\
\text { diverging } \\
\text { channel }\end{array}$ & $0.10,0.20,0.30$ & 45 & $2.54,2.73,3.10$ & $\begin{array}{r}111,713- \\
569,730\end{array}$ & $0.4289-0.5989$ & 1.159 & 1.059 \\
\hline 3 & Austin et al. [4] & $\begin{array}{l}\text { Simple diverg- } \\
\text { ing channel } \\
\text { expansion } \\
(1: 1,2: 3,1: 3 \\
1: 6)\end{array}$ & $\begin{array}{c}0.027,0.044 \\
0.0710 \\
0.0996\end{array}$ & $\begin{array}{l}45,33.69 \\
18.43,9.46\end{array}$ & 5,3 & $\begin{array}{l}17,240- \\
373,495\end{array}$ & $0.05-0.75$ & $\begin{array}{l}1.207 \\
1.190 \\
1.223 \\
1.394\end{array}$ & $\begin{array}{l}1.062 \\
1.057 \\
1.066 \\
1.082\end{array}$ \\
\hline
\end{tabular}

\section{Modelling variables for the non-prismatic channel}

In the following mathematical equations for kinetic energy $(\alpha)$ and momentum correction ( $\beta$ ) coefficients, the independent variables considered are dimensionless flow variables, which depend on the hydraulic, geometric and surface roughness parameters. These non-dimensional parameters are angle of convergence/ divergence $(\theta)$, width ratio $(B / b)$, aspect ratio $(b / h)$ and cross-sectional ratio $(\mathrm{Xr})$ that can be explained as the ratio of the longitudinal distance from the start of the convergence/divergence to the end, and thus it varies from 0 to 1 . The chosen parameters also include Reynolds number $(R e)$ as the ratio of inertial force to the viscous force and Froude's number (Fr) as the ratio of inertial force to gravity force. The characteristics of the above parameters are shown in Fig. $1 \mathrm{~b}$ for the converging channel. The purpose was then to understand the overall effect of independent variable on the dependent $\alpha$ and $\beta$ correction factors. Using these parameters is also justified from the literature since it is known that $a$ and $\beta$ vary with both channel geometric characteristics and flow depths. Keeping these points in mind, one can expect that meaningful empirical regressive functions of $a$ and $\beta$ with the geometric, flow and surface roughness parameters can be obtained.

In summary, all dimensionless parameters can be divided into two categories: geometric parameters such as aspect ratio $(b / h)$, width ratio $(B / b)$, cross-sectional ratio $(\mathrm{Xr})$ and diverging angle $(\theta)$; flow parameters such as Reynolds number $(R e)$ and Froude number $(F r)$.

Thus, the best set of functional relationships between $a$ and $\beta$ correction coefficients and the above-mentioned parameters may be found from different plots of the global 
data sets in the literature. The functions can be expressed in the following forms:

$\alpha=f(\theta, B / b, b / h, \mathrm{Xr}, R e, F r)$

$\beta=f(\theta, B / b, b / h, \mathrm{Xr}, \operatorname{Re}, \mathrm{Fr})$.

\section{Experimental results}

The experimental results are divided into two parts. The first part is the introduction of experimental results from the converging compound channel, and then the second part shows the variation of $a$ and $\beta$ factors with all the independent variables for converging and diverging channels.

\subsection{Experimental results for converging compound channel}

Figure $3 a-c$ shows the stage-discharge relationship for different converging compound channels with different test sections. The equations of best fit with their data are also shown in Fig. 3. The best stage-discharge curve obtained is in the form of power function, $Q=A(H)^{B}$, as shown in Fig. 3a-c for all the five test sections of each converging compound channel; $Q$ represents the discharge, $H$ represents the stage, $A$ and $B$ are constant coefficients. The obtained curves are segregated into two segments: the lower part having a sharp gradient for the inbank flow conditions and the upper part having a mild or moderate gradient for the overbank flow conditions.

The depth-averaged velocity distribution for each cross section was measured at five different sections at a relative depth of 0.3 for all three compound channels with converging floodplains. The results are shown in Fig. 4a, $b$, which demonstrate that the depth-averaged velocity distributions have almost symmetrical patterns at different measurement sections. Figure 4 clearly shows the following effects of the contractions on the velocity distributions: (a) the maximum velocity increases along the channel as the floodplains converge, (b) the velocity in the second half of the converging reach increases significantly
Fig. 3 Stage-discharge curve for compound channel with converging floodplain of angle a $12.38^{\circ}$, b $^{\circ}, \mathbf{c} 5^{\circ}$

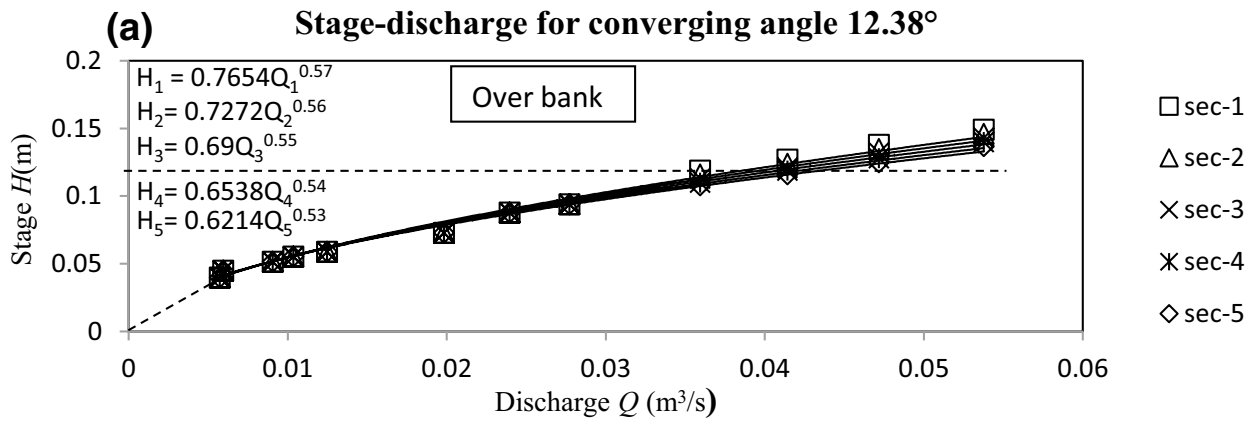

(b)

Stage-discharge for converging angle $9^{\circ}$

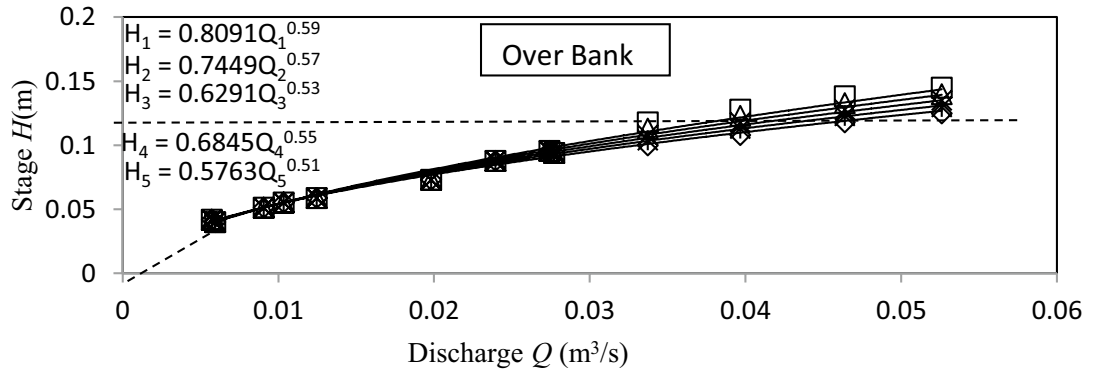

$\square$ sec-1

$\triangle$ sec-2

$\times$ sec-3

$*$ sec-4

$\diamond \sec -5$

(c) Stage-discharge for converging angle $5^{\circ}$

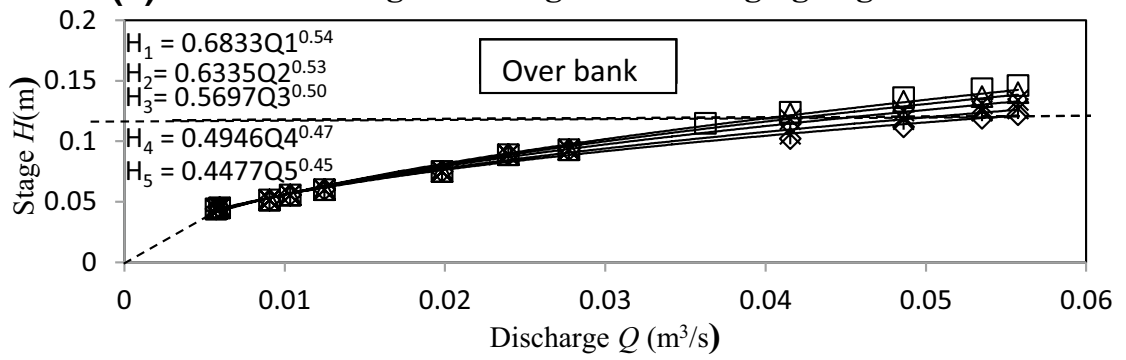

$\square$ sec-1

$\triangle \mathrm{sec}-2$

$\times$ sec-3

*sec-4

$\diamond$ sec-5 
Fig. 4 Depth-averaged velocity distribution of compound channel with converging floodplain of angle a $12.38^{\circ}$ of relative depth $0.3, \mathbf{b} 9^{\circ}$ of relative depth 0.3 and $\mathbf{c} 5^{\circ}$ of relative depth 0.3 (a) Depth average velocity for $C V=12.38^{\circ}$ of $\beta=0.3$

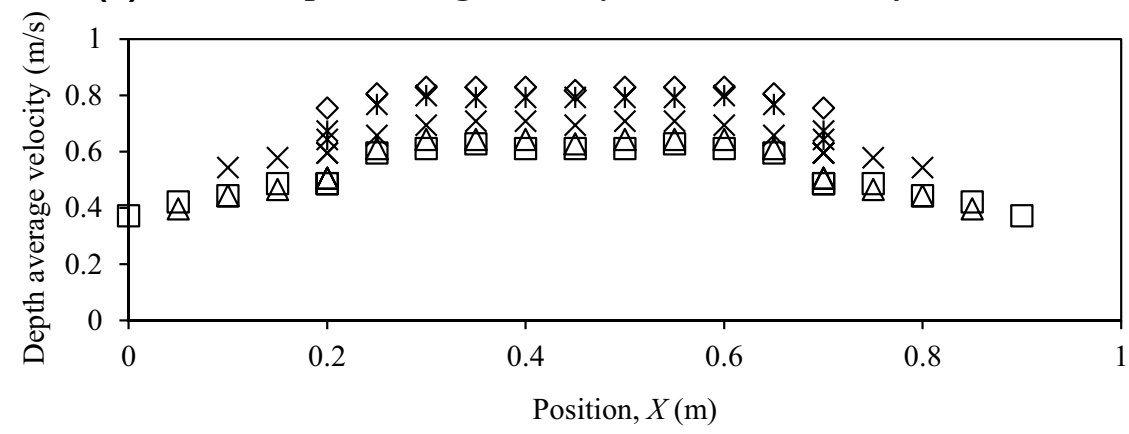

$\diamond \mathrm{sec}-5$

$\square$ sec-1

$\triangle \mathrm{sec}-2$

$\times$ sec-3

*sec-4

(b)

Depth average velocity for $C V=9^{\circ}$ of $\beta=0.3$

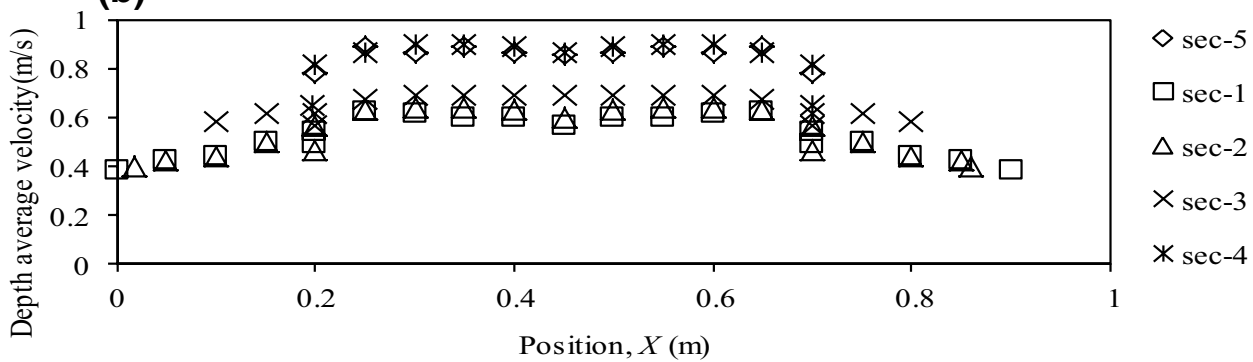

(c) Depth average velocity for $C V=5^{\circ}$ of $\beta=0.3$

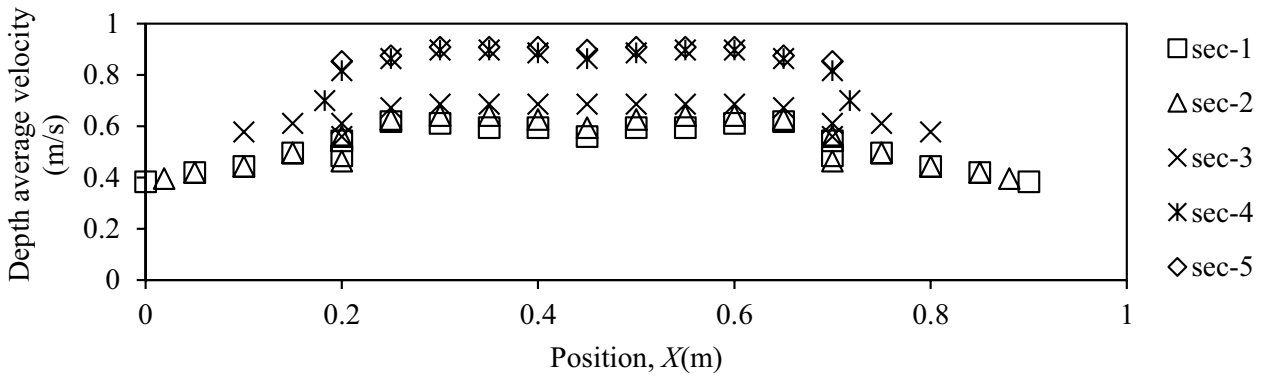

due to water leaving the floodplains and coming into the main channel at the end of the convergence.

\subsection{Model of $\alpha$ and $\beta$ correction coefficients for converging compound channel}

Kinetic energy and momentum correction coefficients have been derived using data of three different types of converging compound channels at Hydraulics Laboratory of NIT, Rourkela, India, along with three data sets of Rezaei [6]. All these channels have homogeneous roughness over main channel and floodplains with Manning's $n$ value of 0.01 . A multiple variable linear regression model has been developed to predict $a$ and $\beta$ through four most influencing dimensionless independent parameters. For a compound channel with non-prismatic floodplain, their relationships are expressed as

$\alpha=F\left(\sigma, \delta, \theta, X_{r}\right)$, where $F$ represents the functional symbol, $\delta$ is the width ratio $(B / b), \sigma$ is the channel aspect ratio $(b / h), \theta$ is the converging angle and $\mathrm{Xr}$ is the relative distance (i.e. $x /$ total non-prismatic length). The kinetic energy and momentum correction coefficients for the best functional relationships have been established from different plots in Figs. 5, 6, 7 and 8.

Figure 5(i) and (ii) shows the variation of $a$ with the independent variables $b / h$ and $\theta$ while keeping $B / b$ constant. This figure indicates that the variation of $\alpha$ correction coefficient with the aspect ratio and angle of convergence follows exponential and power law for the range of data used. For the lower aspect ratio, $a$ value is big and it decreases with increasing aspect ratio. However, this trend is reverse for $a$ vs $\theta$ plot.

Figures 6,7 and $8(\mathrm{i}$, ii) show the variation of $a$ and $\beta$ correction coefficients with other variables such as width ratio $(B / b)$, cross section ratio $(\mathrm{Xr})$, aspect ratio $(b / h)$ and angle 

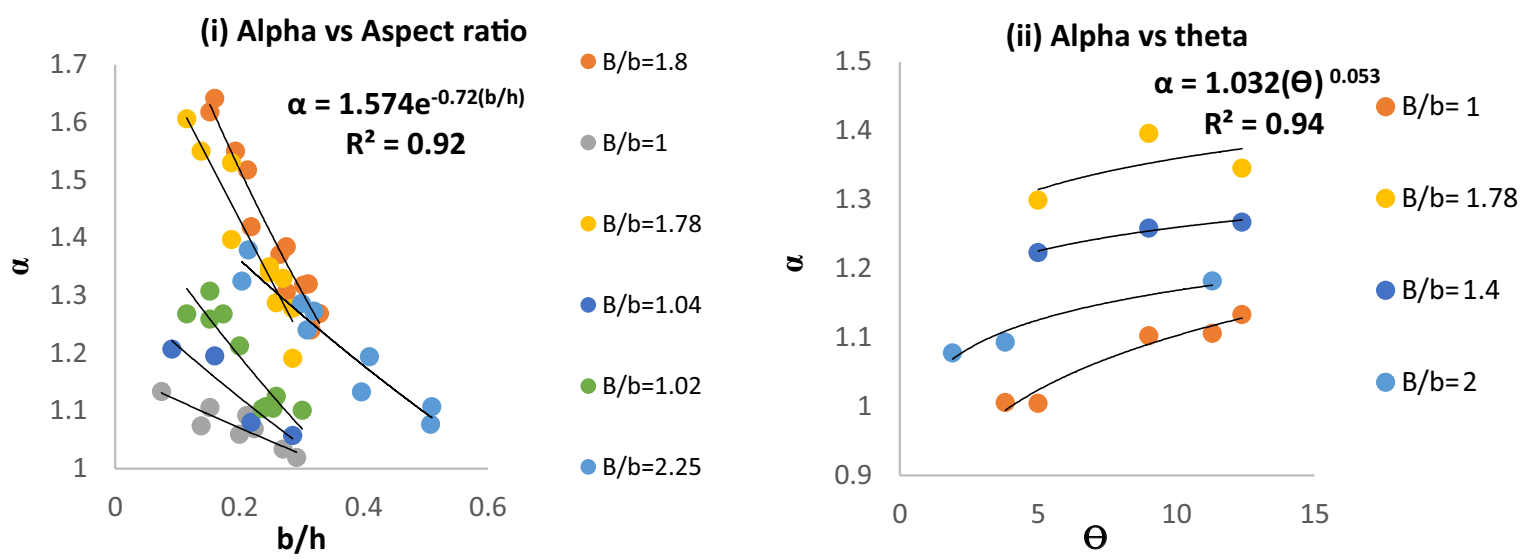

Fig. 5 Variations of the kinetic energy correction coefficients against different aspect ratio $\sigma$ (i) and converging angles $\theta$ (ii)
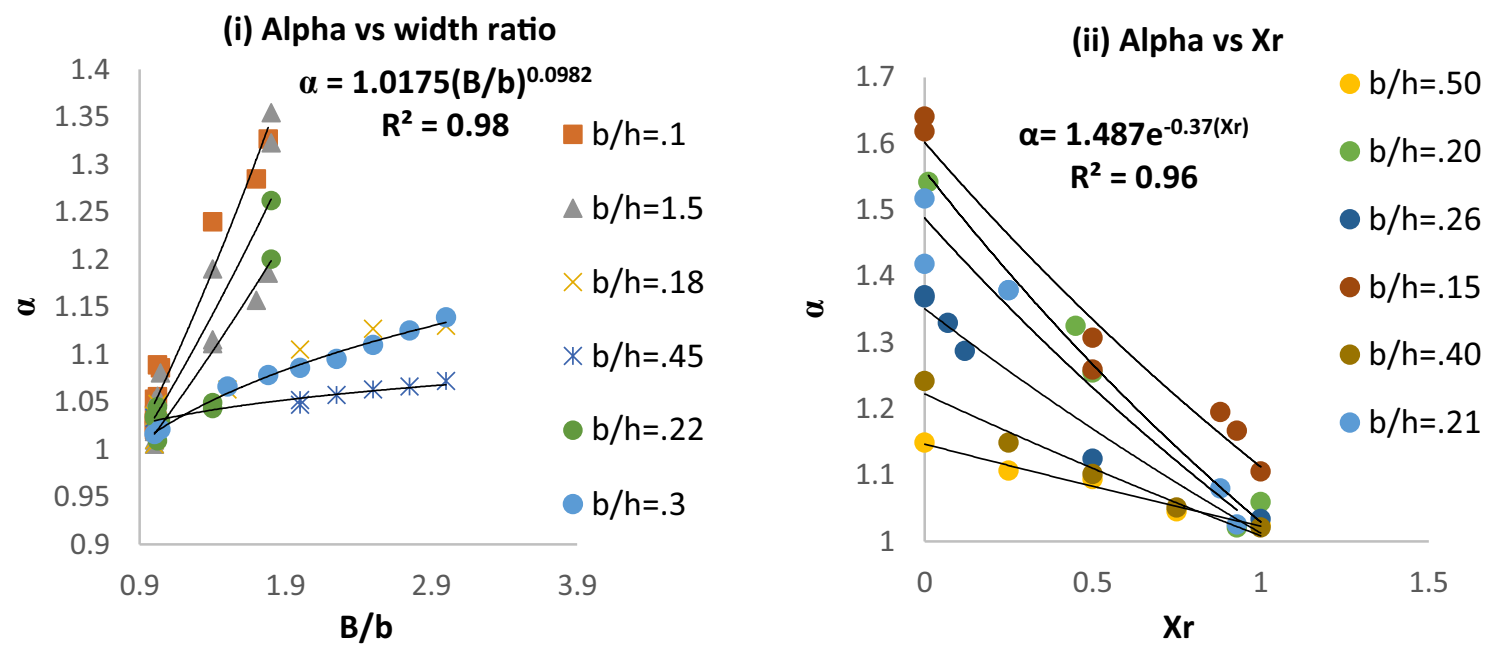

Fig. 6 Variations of the kinetic energy correction coefficients against different width ratio $\sigma$ (i) and relative distance $\operatorname{Xr}$ (ii)
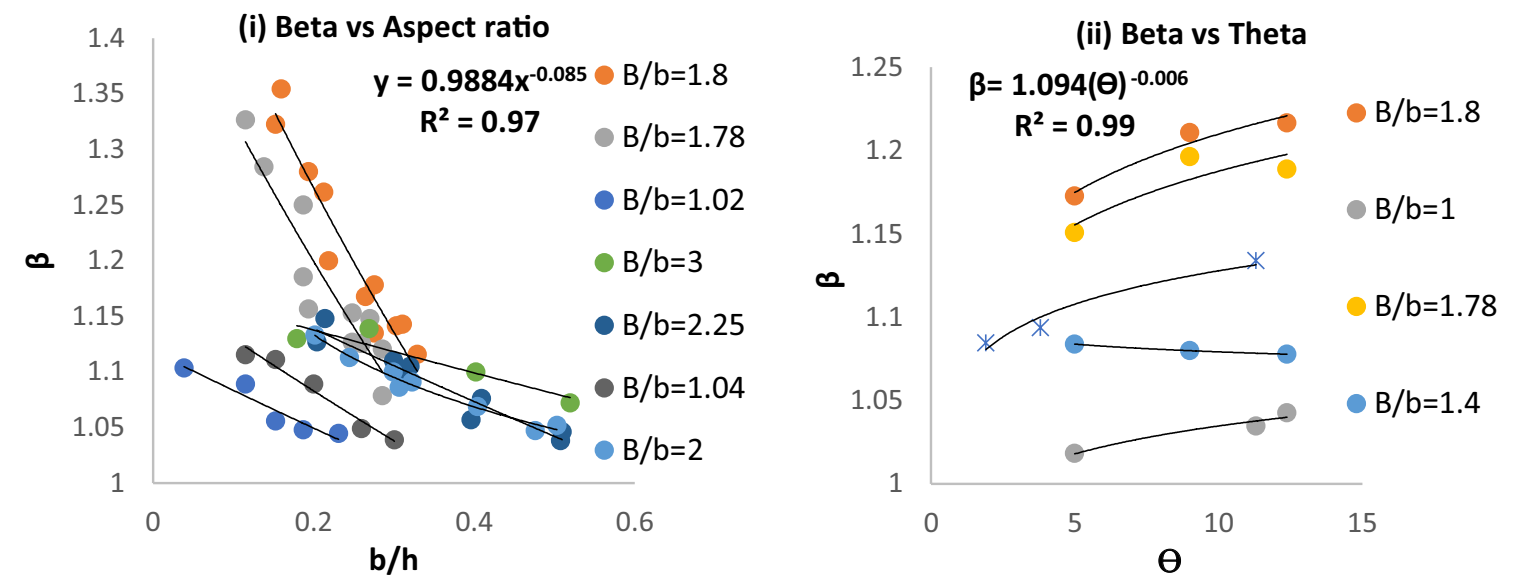

Fig. 7 Variations of the momentum correction coefficients against different aspect ratio $\sigma$ (i) and converging angles $\theta$ (ii) 

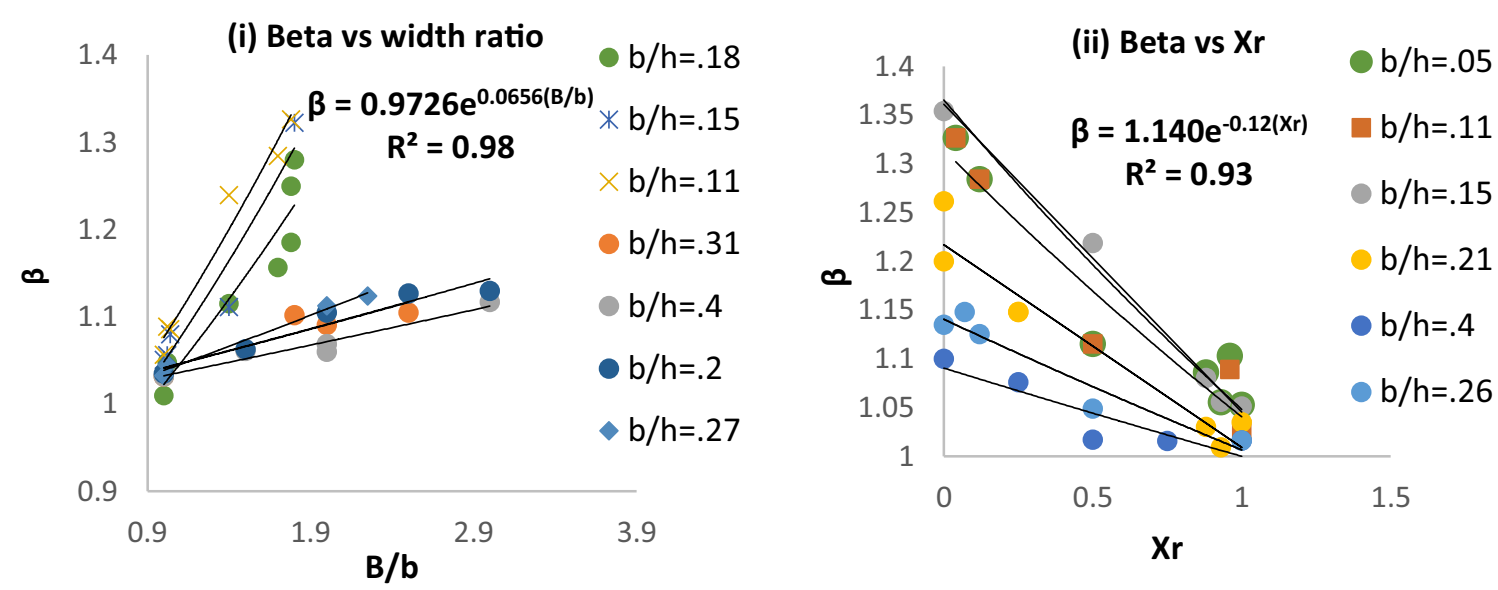

Fig. 8 Variations of the momentum correction coefficients against different width ratio $\sigma$ (i) and relative distance $\operatorname{Xr}$ (ii)

of convergence $(\theta)$, respectively. The variation of $a$ and $\beta$ correction coefficients with the cross section ratio $(\mathrm{Xr})$ shows an interesting trend, i.e. the value of coefficients has a maximum at the entrance $(\mathrm{Xr}=0)$ and it then decreases as distance increases longitudinally (Fig. 6). The impact of angle of convergence in Figs. 5(ii) and 7(ii) shows that $\alpha$ and $\beta$ correction coefficients increase with increasing angles $(1 \leq \theta \leq 12.38)$. Figures 6 (ii) and 7(ii) reveal that the maximum values of 1.64 and 1.35 for $a$ and $\beta$ correction coefficients, respectively, occur at the start of the convergence with the minimum aspect ratio $(b / h)$ of 0.15 . The kinetic energy and momentum correction coefficients decrease with increasing $b / h$ (see Figs. 5i, 7i).

$$
\begin{aligned}
\alpha= & -0.3240+0.4721(\delta)^{0.0982}+0.3681(\theta)^{0.0247} \\
& +0.4090 e^{-0.0726 \sigma}+0.3457 e^{-0.377\left(X_{\mathrm{r}}\right)} \\
\beta= & -0.1308+0.4050 e^{0.0656(\delta)}+0.3664 \theta^{-0.006} \\
& +0.2244(\sigma)^{-0.085}+0.2112 e^{-0.377\left(X_{r}\right)} .
\end{aligned}
$$

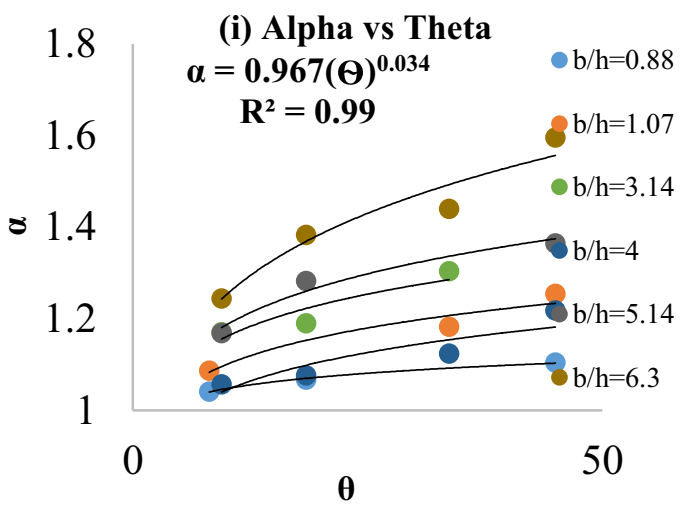

Equations (10) and (11) are obtained based on the experimental data, in which $a$ and $\beta$ correction coefficients are correlated with the variables using multilinear regression. The standard errors for each variable are found within a range (Fig. 16), which makes these equations useful to predict $\alpha$ and $\beta$ with adequate accuracy for converging angle of range $1 \leq \theta \leq 12.38$.

\subsection{Model of $\alpha$ and $\beta$ correction coefficients for diverging compound channel}

In the above section, based on global parameters, Eqs. (10) and (11) have been established for $\alpha$ and $\beta$ correction factors in converging compound channels. A similar attempt has been made for diverging compound channels based on the data from different authors in the literature.

Figures 9,10 and 11 show the variation of $\alpha$ correction coefficients with the independent variables, which are discussed in this section. In addition, Reynolds number and Froude number (Fig. 11i, ii) are considered here as two

Fig. 9 Variations of the kinetic energy correction coefficients against different converging angles $\theta$ (i) and aspect ratio $\omega$ (ii) 

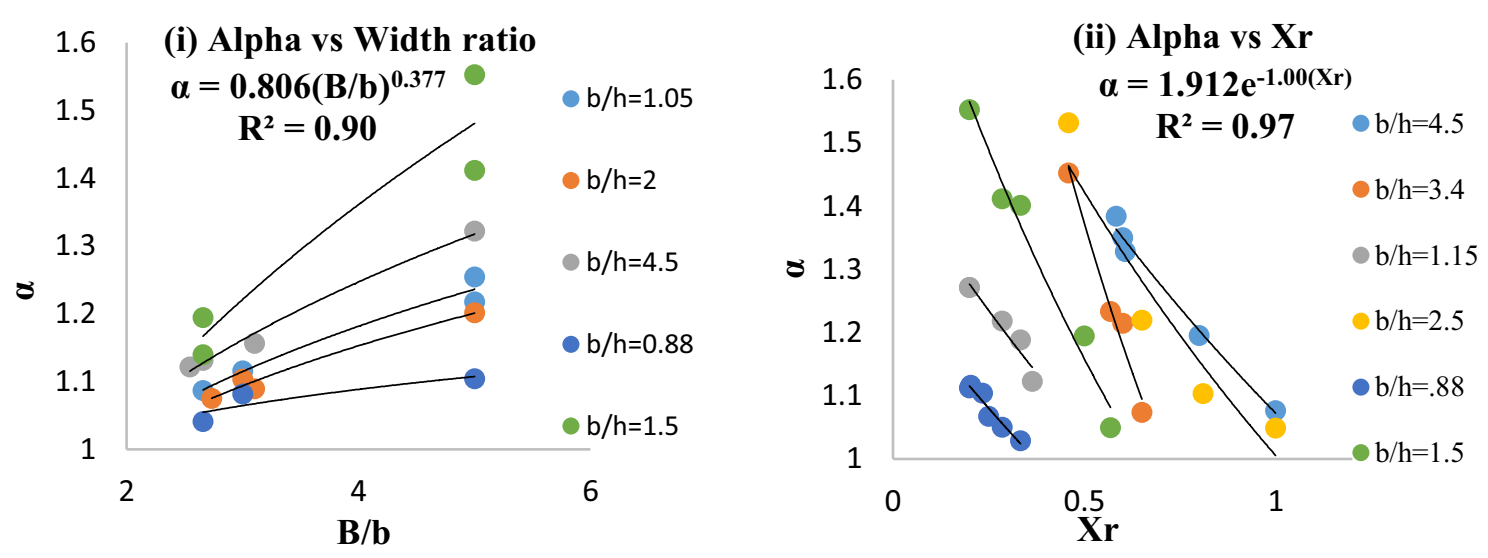

Fig. 10 Variations of the kinetic energy correction coefficients against different width ratio $\sigma$ (i) and relative distance $\mathrm{Xr}$ (ii)
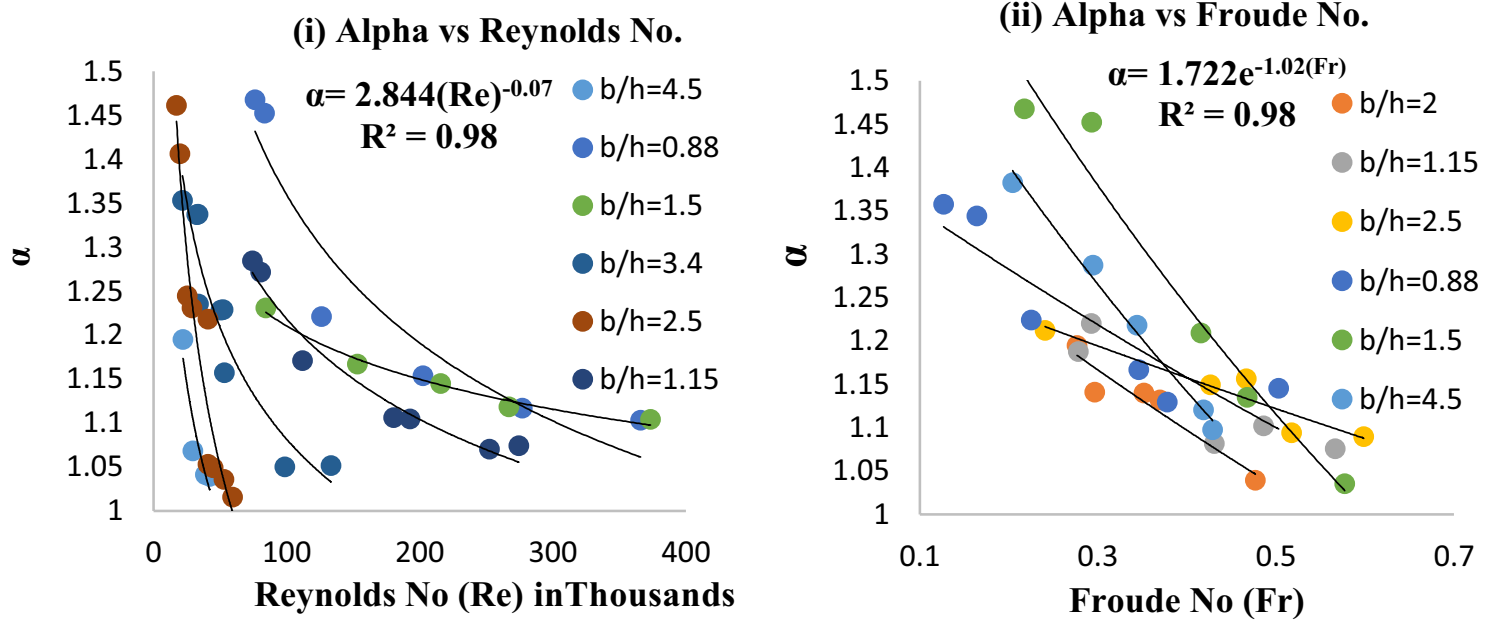

Fig. 11 Variations of the kinetic energy correction coefficients against different Reynolds number (i) and Froude number (ii)

extra non-dimensional flow parameters. These two extra parameters helped in curve fitting for $a$ and $\beta$ correction coefficients more effectively for these particular sets of regression model. Similarly, Figs. 12,13 and 14 show the variation of momentum correction coefficients with the six different variables, which are global and dimensionless flow variables. The maximum value of $a$ and $\beta$ obtained from these data sets are 1.68 and 1.16 , respectively, and the angle of divergence $(\theta)$ varies from 3.13 to 45 .

Figure 14(i, ii) reveals that the effects of Reynolds number and Froude number are important and must be considered in the calculations of $a$ and $\beta$ correction coefficients. It also shows that both $\alpha$ and $\beta$ decrease with the increase in $R e$ and $F r$, which seems quite reasonable because the coefficients should decrease as the turbulence increases.

$$
\begin{aligned}
\alpha= & -0.049+0.424 \theta^{0.074}+0.106(\delta)^{0.377}+0.149 e^{0.1028 *(\sigma)} \\
& +0.122 e^{-1.003(\mathrm{Xr})}+0.713(\operatorname{Re})^{-0.074}+0.0269 e^{-1.023 * F r} \\
\beta= & -0.05484+0.09272 e^{0.0013 * \theta}+0.1248(\delta)^{.0329}+.083024 e^{0.0273(\sigma)} \\
& +0.175 e^{.1302(\mathrm{Xr})}+0.4460(R e)^{-0.029}+0.3154 e^{-0.414 * F r} .
\end{aligned}
$$

Therefore, the final fitted functions for $a$ and $\beta$ are given in Eqs. (12) and (13), respectively. The number of observation and the standard error for each variable in different sets of regression are taken care of in these analyses. Note that these equations can predict $\alpha$ and $\beta$ for the channels with diverging angles in the range $3.13 \leq \theta \leq 45$. 


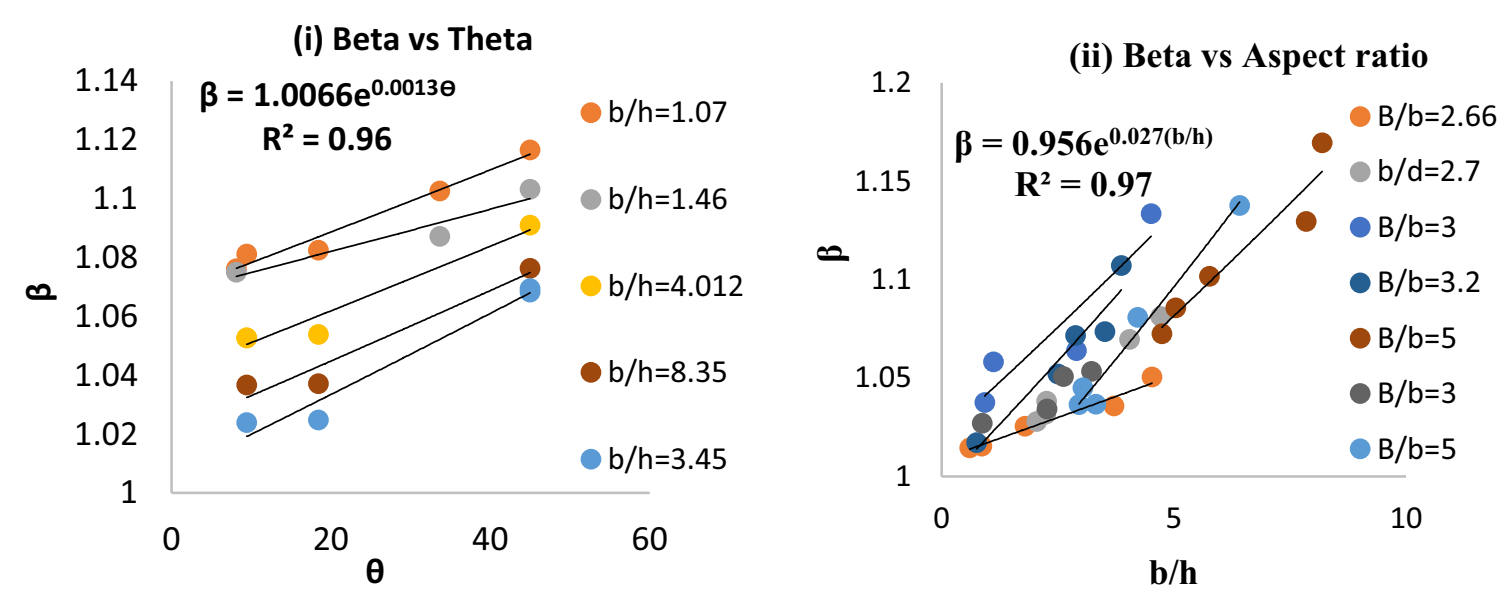

Fig. 12 Variations of the momentum correction coefficients against different aspect converging angles $\theta$ (i) and ratio $\omega$ (ii)
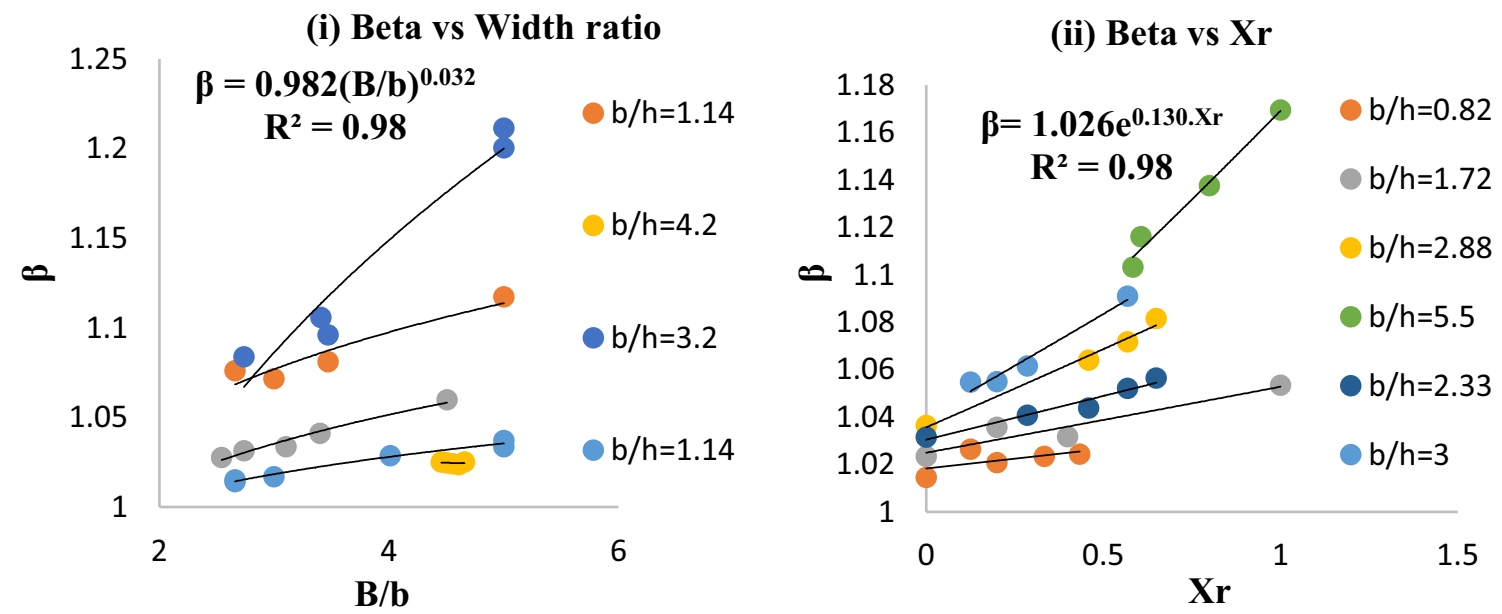

Fig. 13 Variations of the momentum correction coefficients against different width ratio $\sigma$ (i) and relative distance $\mathrm{Xr}$ (ii)

(i) Beta vs Reynolds No

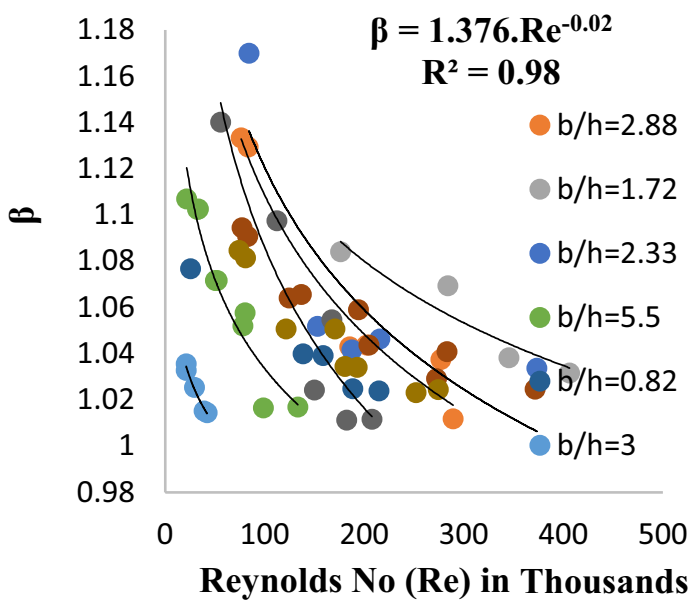

(ii) Beta vs Froude No

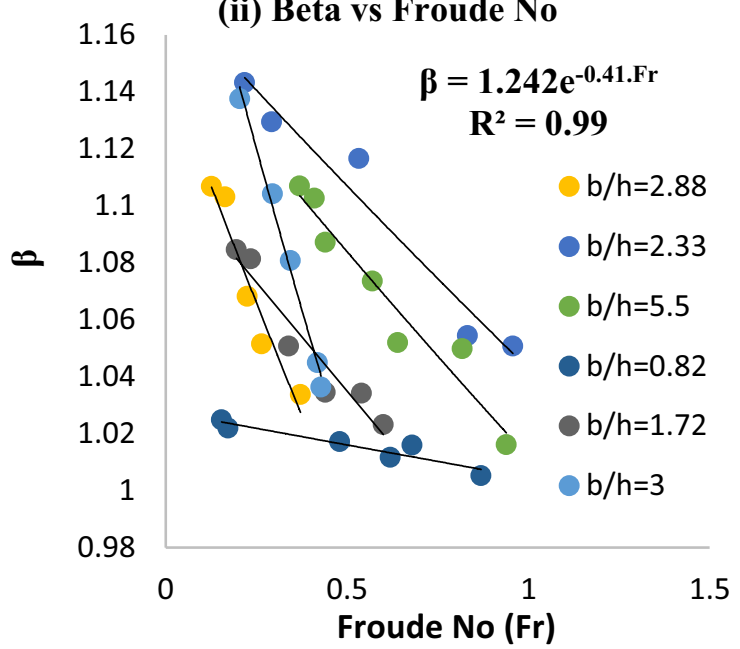

Fig. 14 Variations of the momentum energy correction coefficients against different Reynolds number (i) and Froude number (ii) 


\subsection{Model of $\alpha$ and $\beta$ correction coefficients by gene expression programming}

The development of regression-based model is never-ending because when a new set of data is introduced to the old set of data [31-36], it needs training and regression of curve fitting to produce optimal results. The diversity of the ever-growing data sets is well appreciated by using big data analytics. The authors understand that the model will be uniquely specific when new data are added to the old data sets. Furthermore, new techniques like GEP are convenient since this modelling technique can provide solutions to the problems, which can be easily and realistically performed for new data sets. This new methodology can be helpful to the study of hydrodynamic studies and for river engineers. This philosophy inspired us to move forward the method of curve fitting with the strategy of soft computing. Many soft computing techniques have been explored in the field of water resource like neural networks, fuzzy logic, adaptive neuro-fuzzy, gene programming and many more [31-37]. One such soft computing technique is gene algorithm, which is currently a useful tool for analysing a large data set to explore a potential relationship among the variables involved. The idea of selection, crossover and mutation from gene algorithm is certainly new but eventually highly explored computer programming and simulation technique nowadays. Azamathulla et al. [38] suggested gene expression programming for mathematical expressions, decision tree, polynomial constructs, logical expression, time series forecast, logistic regression, etc. Ferreira [39] developed GEP based on fundamentals of gene development and evolution, which is a selection and rejection process. Guven and Gunal [40], Karbasi and Azamathulla [41] and Pradhan and Khatua [42] used this technique in the field of hydraulics to develop nonlinear mathematical models for local scour around structures, hydraulic jump characteristics and Manning's $n$, respectively.

The two key factors that dominate the gene expression programming are chromosomes and the expressions of the genetic information encoded in the decision tree. The computer programs encoded for any type of the genetic programming are mostly expressed as linear chromosomes, which are finally articulated as the expression trees. The fitness of each chromosomes is evaluated based on fitness function, which is the root-mean-square error (RMSE) used in this study. The fitness function is a quantitative analysis, which helps to identify the capability of model to produce expected value with development over genomes of the progeny [43]. The convergence of such programming is analogous to the number of generation here, which conveys the number of iterations desired to obtain the optimal solution. The chromosomes can be unique single gene (unigenic) or multigenic with equal or unequal programs lengths [42]. The operators used in the generation can be arithmetic, geometric and/or combination of any mathematical expressions.

In the present study, GeneXproTool 5 software has been used for modelling the $a$ and $\beta$ correction coefficients for the converging and diverging channel sets, as mentioned in the previous section. RMSE fitness function produces the most accurate results in modelling references given by Karbasi and Azamathulla [41] and Pradhan and Khatua [42]. Following the same guidelines for the fitness function and selection of sets of training terminals, $70 \%$ for the function $f$ (Eqs. 7, 8) out of 234 inputs were selected for target pairs of the collected data for each $a$ and $\beta$. The remaining percentage of data were used to test the proposed model. The functional set and operational parameters for each data set are given in Table 4, where $\alpha$ and $\beta$ are certainly optimized based on $R^{2}$ and RMSE values.

Based on the proposed GEP model, the simplified analytical form of $a$ and $\beta$ for converging compound channel is expressed as

$\alpha=\frac{\delta}{e^{\mathrm{Xr}+\delta}+67.8718(\sigma)^{2}}+(\delta)^{\frac{\sigma}{9}}\left\{\left(\frac{1}{\sigma}\right)^{\frac{-1}{3}}-1\right\}+\frac{1}{\theta^{3} \sigma\left(2-\frac{12.9518}{\theta}\right)}$
Table 4 Setting criteria for evolution and optimization

\begin{tabular}{lllll}
\hline Parameters for evolving criteria & \multicolumn{5}{l}{ Settings and criteria } & \\
\cline { 2 - 5 } & $\alpha$ (converging) & $\beta$ (converging) & $\alpha$ (diverging) & $\beta$ (diverging) \\
\hline Number of Chromosomes & 30 & 30 & 30 & 30 \\
Head size & 8 & 8 & 8 & 8 \\
Number of genes & 3 & 5 & 5 & 3 \\
Linking function & Addition & Addition & Addition & Addition \\
Program size & 47 & 57 & 47 & 38 \\
Number of generation & 50,000 & 501,206 & 50,703 & 27,468 \\
Constant per gene & 10 & 10 & 10 & 10 \\
Data type & Integer & Integer & Integer & Integer \\
Mutation rate (\%) & 0.040 & 0.030 & 0.030 & 0.030 \\
Crossover frequency (\%) & 50 & 50 & 50 & 50 \\
\hline
\end{tabular}




$$
\begin{aligned}
\beta= & \frac{1}{\log \left(\theta^{-2.0537}+0.0129\right)-6.3987}+\frac{1}{\frac{-1.3692}{x_{r}}-5.8114 \delta^{4} X r}+\frac{1.3274}{e^{\sqrt{x_{r}+\sqrt[3]{\sigma}}}} \\
& +\sigma\left(1-\sqrt[3]{2.37069-\sigma^{1.4928}}\right)+\left(\frac{1}{\left(\frac{1}{x_{r}}-0.4892\right)^{\frac{\sigma 4}{\delta}}}\right)^{5} .
\end{aligned}
$$

Note that the execution of the GEP model in training and testing sets was validated using different error analysis techniques like coefficient of determination $\left(R^{2}\right)$, mean absolute error (MAE), mean absolute percentage error (MAPE) and root-mean-square error (RMSE).

The obtained GEP model for diverging compound channel is:

$$
\begin{aligned}
\alpha= & \ln (2 \sigma-\delta+8.7951)^{\frac{1}{4}}+F r+\frac{1}{(\operatorname{ReXr}-1155.5248 \delta)^{\frac{1}{5}}}-F r^{\frac{1}{5}} \\
& -\frac{2.5147 * 6.4450^{\delta}}{F r e^{\sigma} *(F r-\theta)}+\left(\frac{1}{\left(e^{\mathrm{Xr}}\right)^{\frac{1}{100}}}\right)^{8.6474}
\end{aligned}
$$

\begin{tabular}{|c|c|c|c|c|c|}
\hline Function & Variables & Range (min-max) & SD & Correlations & $\begin{array}{l}\text { Width of uncer- } \\
\text { tainty band } \\
\pm 1.96 \mathrm{Se}\end{array}$ \\
\hline \multirow[t]{4}{*}{$a=f(\theta, B / b, b / h, \mathrm{Xr})$ for converging channel } & $b / h$ & $0.0196-0.522$ & 0.121 & 0.782 & \pm 0.237 \\
\hline & $B / b$ & $1-3$ & 0.673 & 0.511 & \pm 1.319 \\
\hline & $\theta$ & $1.91-12.38$ & 3.855 & 0.083 & \pm 7.555 \\
\hline & $\mathrm{Xr}$ & $0.0001-1$ & 0.395 & 0.147 & \pm 0.774 \\
\hline \multirow[t]{4}{*}{$\beta=f(\theta, B / b, b / h, \mathrm{Xr})$ for converging channel } & $b / h$ & $0.0196-0.522$ & 0.125 & 0.691 & \pm 0.245 \\
\hline & $B / b$ & $1-3$ & 0.686 & 0.403 & \pm 1.346 \\
\hline & $\theta$ & $1.91-12.38$ & 3.824 & 0.159 & \pm 7.496 \\
\hline & $\mathrm{Xr}$ & $0.0001-1$ & 0.397 & 0.102 & \pm 0.778 \\
\hline \multirow[t]{6}{*}{$a=f(\theta, B / b, b / h, \mathrm{Xr}, R e, F r)$ for diverging channel } & $b / h$ & $0.755-8.1967$ & 1.782 & 0.691 & \pm 3.493 \\
\hline & $B / b$ & $2.544-5$ & 1.042 & 0.228 & \pm 2.043 \\
\hline & $\theta$ & $8.13-45$ & 1.461 & 0.182 & \pm 2.865 \\
\hline & $\mathrm{Xr}$ & $0-1$ & 0.336 & 0.053 & \pm 0.658 \\
\hline & $\operatorname{Re}$ & $274.968-1,489,730.64$ & 24.302 & 0.026 & \pm 47.632 \\
\hline & $\mathrm{Fr}$ & $0.0127-0.5668$ & 0.120 & 0.041 & \pm 0.236 \\
\hline \multirow[t]{6}{*}{$\beta=f(\theta, B / b, b / h, X r, R e, F r)$ for diverging channel } & $b / h$ & $0.755-8.1967$ & 1.656 & 0.420 & \pm 3.247 \\
\hline & $B / b$ & $2.544-5$ & 14.886 & -0.830 & \pm 29.178 \\
\hline & $\theta$ & $8.13-45$ & 1.02485 & 0.014 & \pm 2.008 \\
\hline & $\mathrm{Xr}$ & $0-1$ & 0.338 & 0.006 & \pm 0.662 \\
\hline & $\operatorname{Re}$ & $274.968-1,489,730.64$ & $137,186.08$ & -0.004 & \pm 268884.72 \\
\hline & $\mathrm{Fr}$ & $0.0127-0.5668$ & 0.160 & 0.097 & \pm 0.313 \\
\hline
\end{tabular}

$$
\beta=\frac{1}{\theta(\theta+\sigma)-8.0559(\sigma)^{2}}+1.0846-\frac{3.9470 e^{\mathrm{Xr}}}{\sigma}+\frac{1}{\theta \sigma(\theta-1.8428)\left(34.4958-\frac{1}{F r}\right)}
$$

Table 5 Function dependency on parameters 
the relationship between two variables. It varies from -1 to 1 , where 1 signifies the strong agreement between two variables and -1 shows the least agreement.

Table 5 shows that the correlation of aspect ratio $(b / h)$ is much higher, and it plays a significant role in all the functions. The width ratio $(B / b)$ also affects the function in a prolific way, but the variables like angle and distance of cross section is comparably less significant in most of the models. The value $R^{2}$ also helps in identifying a best possible independent variable for curve fitting. For example, a negative correlation for the variables like $B / b$ ratio and $R e$ has adversely affected the $\beta$ model for diverging compound channels, where the model having $R^{2}$ value of 0.53 was not an acceptable limit. However, removing such variables with least dependability has improved the model significantly. Similarly, in the $a$ and $\beta$ models for converging compound channels, the variables like $R e$ and Fr have negative correlations and yield a curve fitting model with very small $R^{2}$ value.

The accuracy of the proposed models is also checked through RMSE and $\mathrm{R}^{2}$, which can be expressed as:

$\operatorname{RMSE}=\sqrt{\frac{\sum_{i=1}^{n}\left(O_{i}-P_{i}\right)^{2}}{N}}$

$R^{2}=\frac{\left(\sum_{i=1}^{n}\left(O_{i}-\bar{O}_{i}\right)\right)}{\sum_{i=1}^{n}\left(O_{i}-\bar{O}_{i}\right)^{2} \sum_{i=1}^{n}\left(P_{i}-\bar{P}_{i}\right)^{2}}$,

where $O_{i}$ is the observed value, $P_{i}$ is the predicted value, $\bar{O}_{i}$ is the mean value of the observations, $\bar{P}_{i}$ is the mean value of predictions, $i$ is the subscript which indicates the term number of the data and $N$ is the total number of data. Table 6 shows the performance of each model. The uncertainty of any model can be described as the quantitative evaluation of prediction errors. The mean $\bar{e}=\sum_{i=1}^{n} e_{i}$ and the standard deviation $S_{e}=\sqrt{\sum_{i=1}^{n} \frac{\left(e-\bar{e}_{i}\right)^{2}}{n-1}}$ of the model prediction errors $\left(e_{i}=P_{i}-Q_{i}\right)$ were also calculated for the observed value, where a positive mean value implies that the model is over-estimated and a negative implies underestimated. Karbasi and Azamathulla [41] suggested that as per Wilson score, values of $\bar{e}$ and $S_{e}$ can be used to define the confidence band. The value of $\pm 1.96 S_{e}$ yields approximately $95 \%$ confidence band [44]. Table 5 suggests the width of uncertainty band and the $95 \%$ prediction interval errors. The range is self-justifying the dependency of the variable on the function.

\section{Validation of the derived model}

Based on multilinear regression (MLR) (Eqs. 10-13) and gene progression programming (GEP) (Eqs. 14-17), the proposed models for $a$ and $\beta$ correction coefficients have been tested by the validation data. The comparison between observed and calculated $\alpha$ and $\beta$ is presented in Figs. 15 and 16, respectively, for the converging and diverging models. The plots obtained for the GEP in all models have a higher $R^{2}$ value (Table 6).

The first set of validation results in Fig. 15 shows some scatter for the models in converging channels. For the validation (test) and training data sets, the coefficient of determination for the developed GEP is higher, which shows good reliable results for the estimated $a$ and $\beta$. On the other hand, Fig. 16 shows the performance of MLR and GEP models for $\alpha$ (Fig. 16i, ii) and $\beta$ (Fig. 16iii, iv) calculations for diverging channels. The overall value for coefficients of determination shows that the GEP model is more reliable and better than the MLR model.

\section{Application of the model to natural river system}

A natural river system is considered in this study to calculate the values of $a$ and $\beta$ for converging and diverging sections of the Kaskaskia River of Utah. The report "Hydraulics of flow studied for two reaches of Kaskaskia River" by Bhowmik [45] was used for the same. There were two reaches with 17 and 15 cross sections, respectively.
Table 6 Performance of models

\begin{tabular}{llllll}
\hline & Model & $R^{2}$ (training) & RMSE (training) & $R^{2}$ (test) & RMSE (test) \\
\hline MLR & $\alpha$ (converging) & 0.91 & 0.089 & 0.72 & 0.160 \\
& $\beta$ (converging) & 0.90 & 0.147 & 0.75 & 0.740 \\
& $\alpha$ (diverging) & 0.91 & 0.098 & 0.72 & 0.140 \\
& $\beta$ (diverging) & 0.89 & 0.077 & 0.78 & 0.048 \\
GEP & $\alpha$ (converging) & 0.95 & 0.021 & 0.93 & 0.031 \\
& $\beta$ (converging) & 0.94 & 0.024 & 0.93 & 0.027 \\
& $\alpha$ (diverging) & 0.96 & 0.013 & 0.97 & 0.115 \\
& $\beta$ (diverging) & 0.91 & 0.030 & 0.94 & 0.014 \\
\hline
\end{tabular}



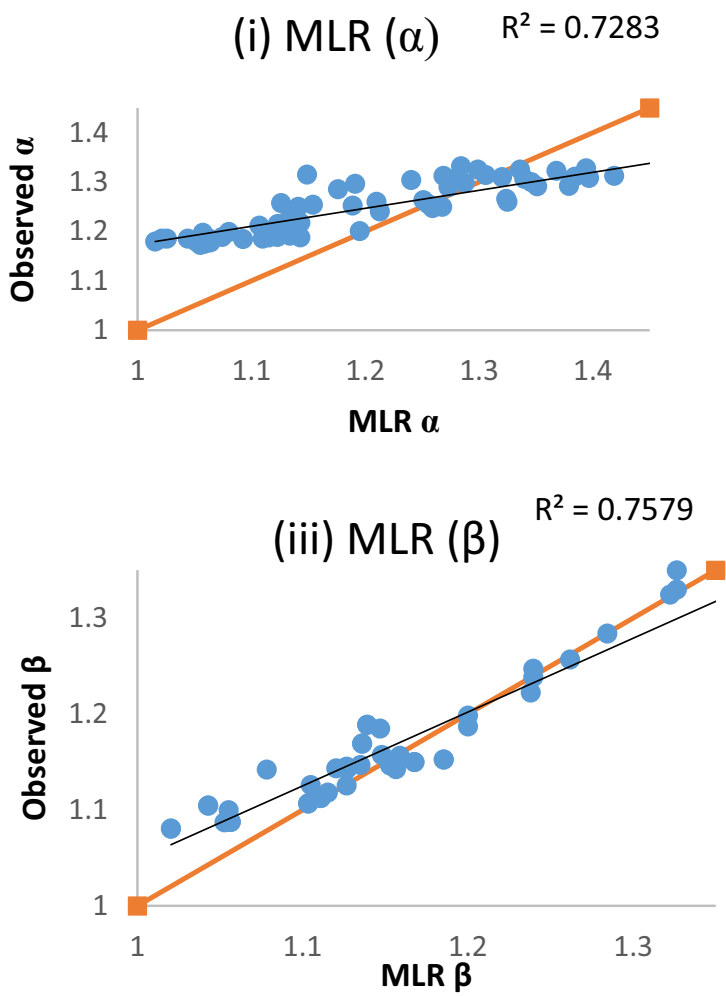

(ii) $\operatorname{GEP}(\alpha) \quad \mathrm{R}^{2}=0.9344$

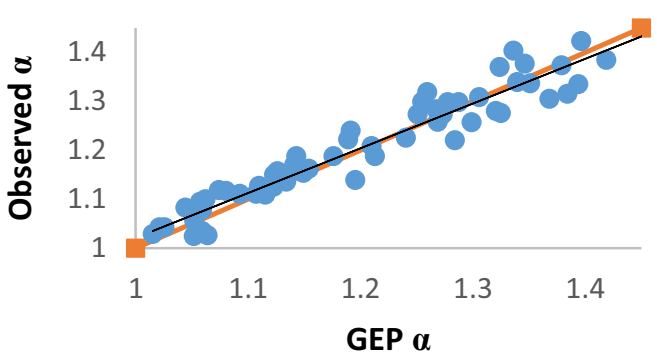

(iv) GEP ( $\beta) \quad R^{2}=0.9356$

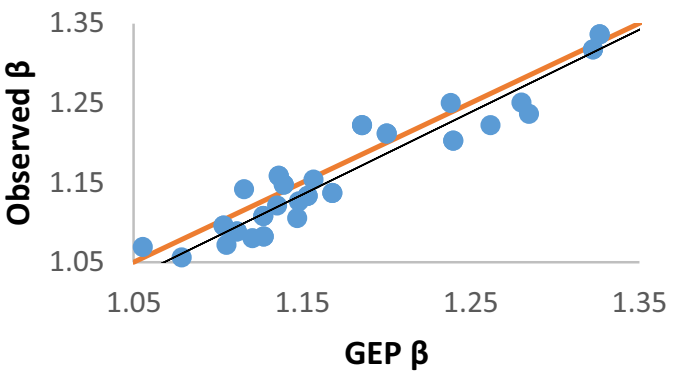

Fig. 15 Performance of converging channel $\alpha$ (i, ii) using Eq. 10 and 14 and $\beta$ (iii, iv) using Eqs. 11 and 15 model for validation set, respectively

However, out of these available cross sections only four cross sections in Reach 1 downstream of man-made lake Shelbyville were straight, and seven cross sections in Reach 2 downstream of another man-made lake Carlyle were straight. For both reaches, three different discharges were categorically distinguished as low flow (Reach 1 at $58 \mathrm{cfs}$; Reach 2 at $290 \mathrm{cfs}$ ), medium flow (Reach 1 at 1420 cfs; Reach 2 at $2160 \mathrm{cfs}$ ) and high flow (Reach 1 at 4000 cfs; Reach 2 at 3700 cfs). Thus, there are totally six sets of measured $\alpha$ and $\beta$ values in two different reaches, which have different hydraulic and bed characteristics. Figure 17 shows the plan view of Reach 1 and 2 with straight cross sections for 1, 2, 3 and 4 in Reach 1, and 1, 2, 10, 11, 12, 14 and 15 in Reach 2, respectively, which has been used in many different studies and found reliable [46-50].

Among all cross sections in both reaches, only such cross sections were considered where they have straight non-prismatic configuration and also have hydraulic characteristics under the range of parameters for which the models are developed. All the parameters considered for this study are given in Table 7(a)-(c).

Figure 18 shows the comparison of $a$ and $\beta$ obtained from the models. The plot includes both $\alpha$ and $\beta$ at every cross section for Reach 1 and Reach 2 . Every reach and cross section is named according to the number, for example Lake Shelbyville Reach 1 is identified as R1 and its first cross section is named as $X 1$. Similarly, cross section 10 in Lake Carlyle Reach 2 is denoted as R2X10. All the notations for every combination are also described in the remark column of Table 7.

In Fig. 18a-c, calculated $\alpha$ and $\beta$ are plotted against the actual $\alpha$ and $\beta$ taken from the report by Bhowmik [45]. The GEP model in most of the cross sections performs well compared to the MLR model. The overall mean percentage error for the GEP and MLR models is given in Table 8 for $a$ and $\beta$ correction coefficients at all flow events.

The mean percentage error of the GEP model has the least value of $12.67 \%$ for low flow event. For the $\beta$ model, the least mean percentage error is found for the MLR model, which is much better in comparison with the $a$ model. The range of errors by GEP is $12-15 \%$ for the $a$ model, which is smaller than $18-25 \%$ by the MLR model. On the other hand, the $\beta$ model has rather contradictory results, showing a reasonable range of $6-8 \%$ in mean percentage error for the MLR and 7-15\% for the GEP model. 

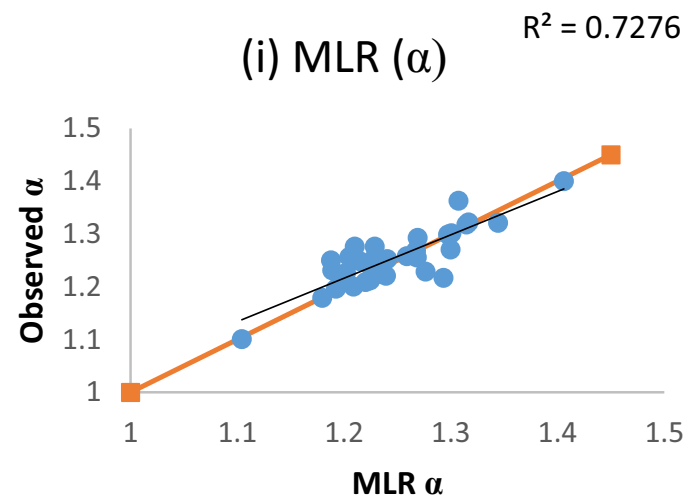

(iii) $\operatorname{MLR}(\beta)$

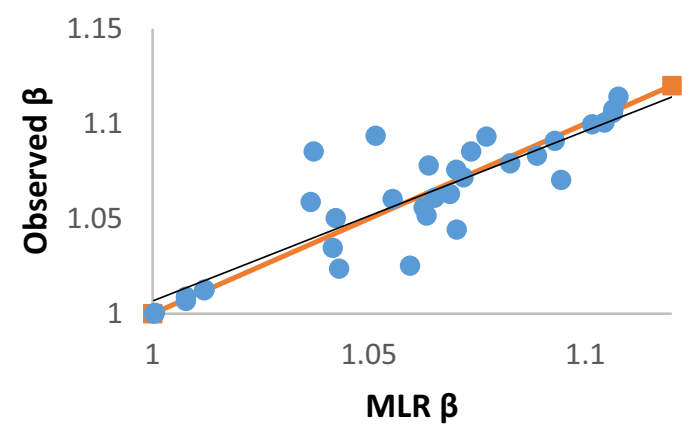

(ii) $\operatorname{GEP}(\alpha)$

$R^{2}=0.9724$

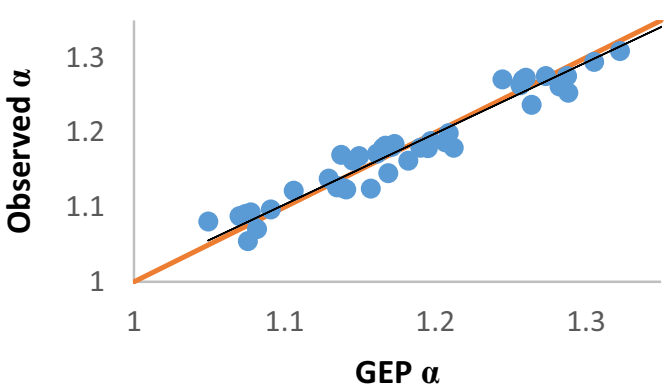

(iv) $\operatorname{GEP}(\beta)$

$R^{2}=0.9942$

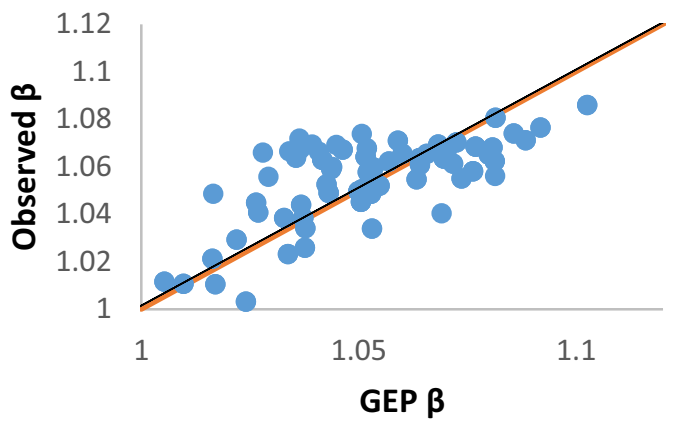

Fig. 16 Performance of diverging channel $\alpha$ (i, ii) using Eqs. 12 and 16 and $\beta$ (iii, iv) using Eqs. 13 and 17 model for validation set, respectively

\section{Conclusions}

A comparison of conventional multilinear regression technique for curve fitting with the new gene expression programming has been carried out with analytical overview for the independent variable dependency on function of $a$ and $\beta$ for non-prismatic channels. The model of $\alpha$ and $\beta$ has been developed based on three new sets of experimental data for converging compound channel, along with a wide range of experimental data sets from other authors in the literature. The range of data (Table 5) includes both large- and small-scale data. The wide range of data sets is used to develop the new model showing the scope of wider applicability.

The proposed models were validated by independent experimental and natural river data. The results show that the GEP model (Eqs. 14-17) performed well for the validation set of data with better coefficient of determination
$\mathrm{R}^{2}$ and RMSE. However, in the case of natural river system, although the GEP model for a (Eqs. 14, 16) has better results over the MLR model, the MLR (Eqs. 11, 13) has outperformed the GEP model in the calculation of $\beta$. The range of errors for the GEP model is less than $16 \%$, which can be categorized as satisfactory results when it comes to natural river system, because the range of independent variables in natural river system was out of bound at many significant cross sections. The range of variables plays a significant role for models, which are developed through curve fitting, since the root of the model can lie in both local and global minima and maxima.

In the process of curve fitting, the other interesting analysis was the sensitivity of the variables used in the model. The most sensitive independent variable found in this study was the aspect ratio $(b / h)$, which has higher correlation and least standard deviation. This is not surprising because the velocity distribution is largely 


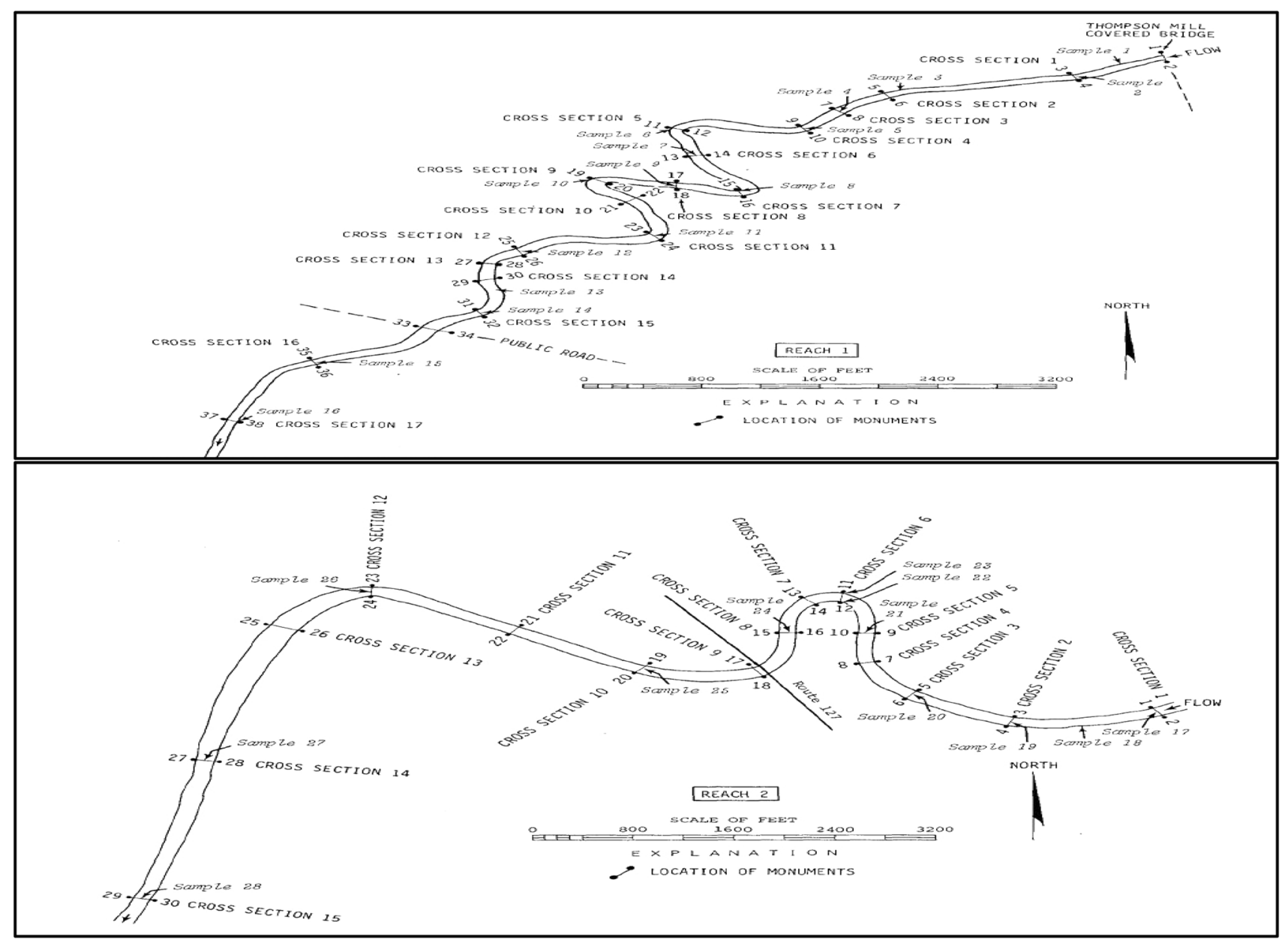

Fig. 17 Plain view of Reach 1 and 2 (hydraulics of flow in the Kaskaskia River, Illinois [45])

affected by the depth of flow in main channel. Another most substantial parameter is the width ratio $(B / b)$, which also has noteworthy effect on the lateral velocity distribution over the cross section. However, the angle of convergence/divergence $(\theta)$ and cross-sectional ratio $\left(X_{r}\right)$ have the least effect on the models as they have very low correlation coefficients. The other parameters like Reynolds number and Froude number would help in the curve fitting for diverging channels since the data sets for the other dependent variables were limited. Nevertheless, these flow parameter variables have low correlation coefficients and higher band of uncertainty. 
Table 7 Channel

characteristics for (a) low flow event, (b) medium flow event and (c) high flow event for reach 1 and reach 2

\begin{tabular}{llllllllll}
\hline Cross section & $B / b$ & $b / h$ & $\theta$ & $\mathrm{Xr}$ & $R e$ & $\mathrm{Fr}$ & $\alpha$ & $\beta$ & Remarks \\
\hline $\begin{array}{l}\text { (a) Low flow event } \\
\text { Reach 1-Shelbyville Lake }\end{array}$ & & & & & & & & & \\
XS1 & 1.5985 & 1.2067 & 2.18 & 0 & $1,130,142$ & 0.12 & 1.62 & 1.22 & Diverging R1X1 \\
XS2 & 2.088 & 1.0856 & 1.08 & 0.1686 & $924,526.1$ & 0.12 & 1.39 & 1.14 & Diverging R1X2 \\
XS3 & 4.0329 & 0.7326 & 1.69 & 0.2027 & $1,047,342$ & 0.13 & 1.33 & 1.12 & Converging R1X3 \\
XS4 & 5.9030 & 0.3911 & 1.28 & 0.2336 & $1,074,338$ & 0.13 & 1.25 & 1.09 & Converging R1X4 \\
Reach 2-Carlyle Lake & & & & & & & & \\
XS1 & 3.1640 & 2.5508 & 2.88 & 0 & $236,223.3$ & 0.14 & 1.64 & 1.19 & Converging R2X1 \\
XS2 & 4.5424 & 1.7110 & 2.34 & 0.1133 & $277,498.3$ & 0.16 & 1.75 & 1.23 & Diverging R2X2 \\
XS10 & 6.9435 & 0.8106 & 0.79 & 0.4404 & $291,985.2$ & 0.08 & 2.66 & 1.54 & Converging R2X10 \\
XS11 & 3.4015 & 1.2987 & 0.5346 & 0.52234 & $300,144.5$ & 0.06 & 1.87 & 1.3 & Converging R2X11 \\
XS14 & 2.9665 & 1.6810 & 0.3232 & 0.8382 & $290,340.9$ & 0.067 & 1.69 & 1.27 & Diverging R2X14 \\
XS15 & 2.6740 & 2.3040 & 0.2436 & 1 & 238,669 & 0.070 & NA & NA & Converging R2X15
\end{tabular}

(b) Medium flow event

Reach 1-Shelbyville Lake

$\begin{array}{crllllllll}\text { XS1 } & 1.0002 & 1.5448 & 2.07 & 0 & 1,370,819 & 0.02 & 1.95 & 1.38 & \text { Diverging R1X1 } \\ \text { XS2 } & 1.3061 & 1.5623 & 1.05 & 0.1686 & 1,136,365 & 0.02 & 1.83 & 1.38 & \text { Diverging R1X2 } \\ \text { XS3 } & 3.0009 & 0.8704 & 1.35 & 0.2027 & 1,225,971 & 0.03 & 1.6 & 1.25 & \text { Converging R1X3 } \\ \text { XS4 } & 2.0838 & 0.8913 & 0.72 & 0.2336 & 1,304,598 & 0.02 & 1.57 & 1.24 & \text { Converging R1X4 } \\ \text { Reach 2-Carlyle Lake } & & & & & & & & \\ \text { XS1 } & 1.2573 & 1.5906 & 0.78 & 0 & 1,627,586 & 0.02 & 1.14 & 1.03 & \text { Converging R2X1 } \\ \text { XS2 } & 1.8951 & 1.0407 & 1.28 & 0.1133 & 2,074,494 & 0.02 & 1.33 & 1.12 & \text { Diverging R2X2 } \\ \text { XS11 } & 2.3521 & 0.9356 & 0.39 & 0.5223 & 2,013,372 & 0.02 & 1.2 & 1.07 & \text { Converging R2X11 } \\ \text { XS12 } & 2.5606 & 0.6436 & 0.29 & 0.6130 & 2,060,798 & 0.02 & 1.19 & 1.07 & \text { Converging R2X12 } \\ \text { XS14 } & 2.5836 & 0.7540 & 0.27 & 0.8381 & 1,865,059 & 0.01 & 1.23 & 1.09 & \text { Diverging R2X14 } \\ \text { XS15 } & 2.1363 & 0.9314 & 0.20 & 1 & 1,552,498 & 0.01 & 1.22 & 1.07 & \text { Converging R2X15 }\end{array}$

(c) High flow event

Reach 1-Shelbyville Lake

\begin{tabular}{llllllllll} 
XS1 & 1.0433 & 0.96853 & 2.09 & 0 & $3,294,148$ & 0.02 & 1.47 & 1.14 & Diverging R1X1 \\
XS2 & 1.2303 & 0.9364 & 7.76 & 0.1687 & $3,099,189$ & 0.02 & 1.39 & 1.13 & Diverging R1X2 \\
XS3 & 2.403 & 0.5684 & 0.79 & 0.2027 & $3,134,189$ & 0.02 & 1.43 & 1.14 & Converging R1X3 \\
XS4 & 1.5086 & 0.6704 & 4.68 & 0.2336 & $3,205,426$ & 0.02 & 1.44 & 1.15 & Converging R1X4 \\
Reach 2-Carlyle Lake & & & & & & & & \\
XS1 & 1.4364 & 0.9927 & 1.15 & 0 & $1,854,792$ & 0.12 & 1.36 & 1.13 & Converging R2X1 \\
XS2 & 1.7964 & 0.8435 & 1.20 & 0.1133 & $2,416,307$ & 0.15 & 1.45 & 1.16 & Diverging R2X2 \\
XS10 & 2.3147 & 0.7251 & 4.74 & 0.4404 & $12,293,805$ & 0.04 & 1.54 & 1.23 & Converging R2X10 \\
XS11 & 3.2683 & 0.4353 & 4.72 & 0.5223 & $17,312,552$ & 0.07 & 1.44 & 1.16 & Converging R2X11 \\
XS12 & 2.1144 & 0.5818 & 2.50 & 0.6130 & $5,933,683$ & 0.08 & 1.26 & 1.1 & Converging R2X12 \\
XS14 & 2.4702 & 0.6108 & 2.61 & 0.8381 & $7,224,398$ & 0.09 & 1.51 & 1.2 & Diverging R2X14 \\
XS15 & 1.8053 & 0.8152 & 1.73 & 1 & $3,510,988$ & 0.10 & 1.4 & 1.16 & Converging R2X15 \\
\hline
\end{tabular}


Fig. 18 Comparative plot for $a$ and $\beta$ obtained from MLR and GEP model for a low flow event, $\mathbf{b}$ medium flow event and $\mathbf{c}$ high flow event (a)
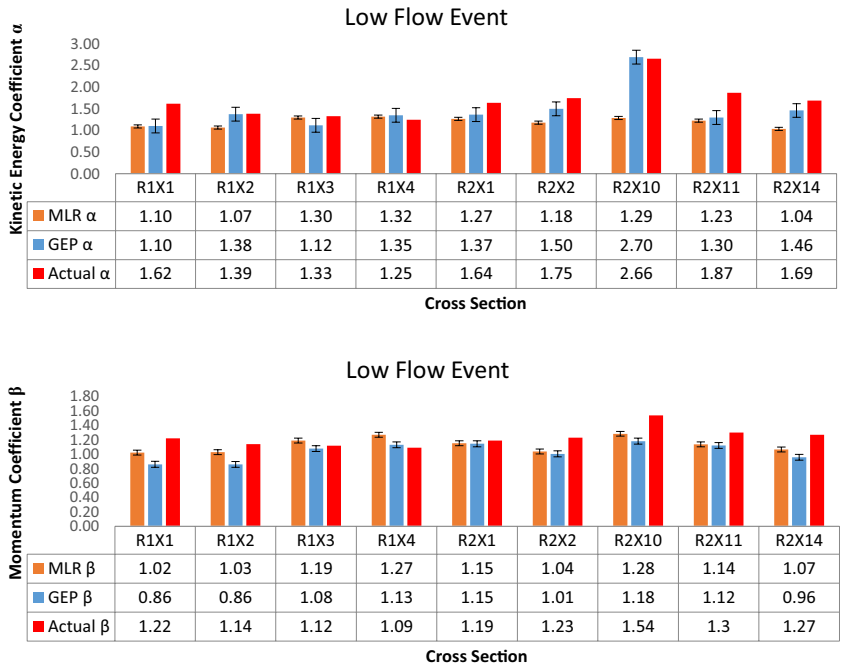

(b)
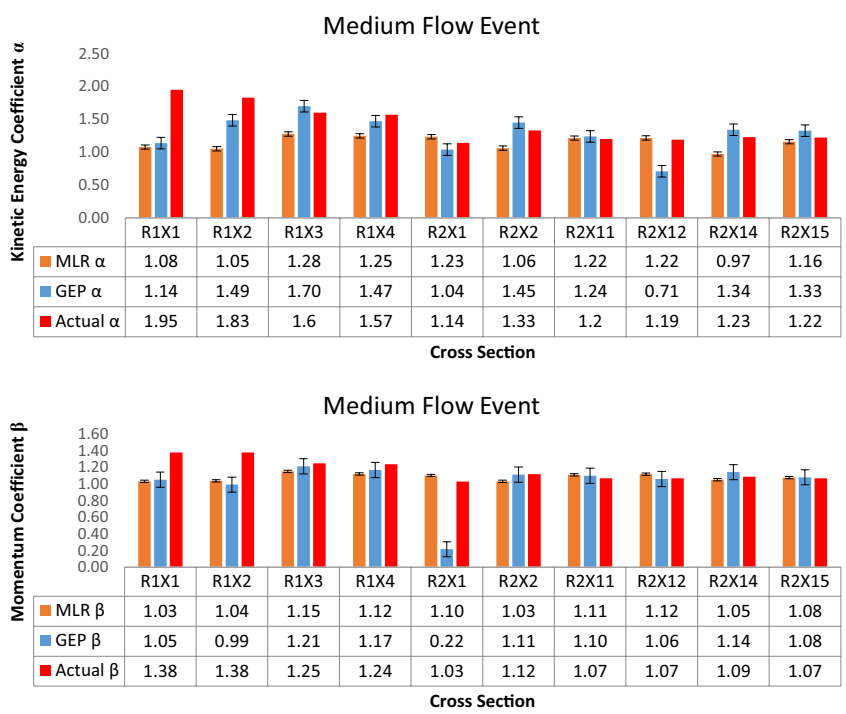

(c)

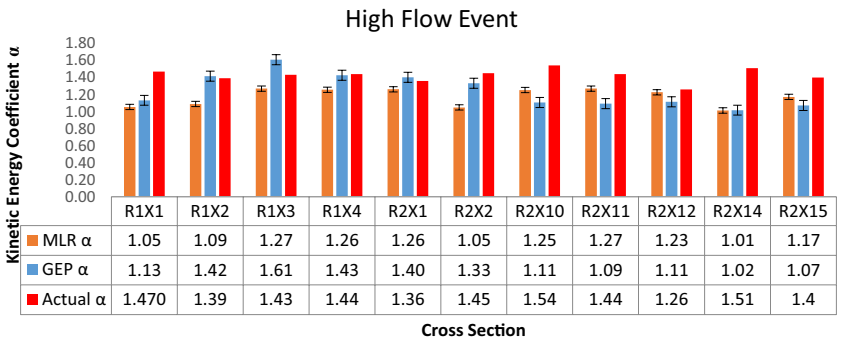

High Flow Event

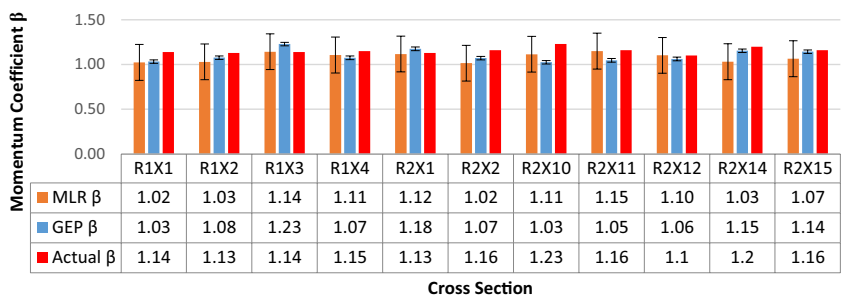


Table 8 Mean percentage error obtained for modelled $a$ and $\beta$

\begin{tabular}{llllllc}
\hline Event & Low MLR (\%) & Low GEP (\%) & Medium MLR (\%) & Medium GEP (\%) & High MLR (\%) & High GEP (\%) \\
\hline$a$ & 25.74 & 12.62 & 18.57 & 15.23 & 17.41 & 15.40 \\
$\beta$ & 7.45 & 15.35 & 6.19 & 14.92 & 6.30 & 6.80 \\
\hline
\end{tabular}

Acknowledgements The authors wish to acknowledge the support from the National Institute of Technology, Rourkela, and the UGC UKIERI Research Project (Ref No. UGC-2013 14/017). We would also like to gratefully reciprocate to Dr. K. K. Khatua and Dr. Bandita Naik for providing data sets from their experiments conducted in NIT Rourkela.

\section{Compliance with ethical standards}

Conflict of interest The authors declare that they have no competing interests.

\section{References}

1. Chen $C L$ (1992) Momentum and energy coefficients based on power-law velocity profile. J Hydraul Eng 118(11):1571-1584

2. AL-Khatib IA, Göğüş M (1999) Momentum and kinetic energy coefficients in symmetrical rectangular compound cross section flumes. Turk J Eng Environ Sci 23(3):187-198

3. Seckin G, Ardiclioglu M, Cagatay H, Cobaner M, Yurtal R (2009) Experimental investigation of kinetic energy and momentum correction coefficients in open channels. Sci Res Essays 4(5):473-478

4. Austin LH, Skogerboe GV, Bennett RS (1970) Subcritical flow at open channel structures open channel expansions. Ph.D. thesis, Utah State University

5. Alauddin M, Basak BC (2006) Development of an expansion transition in open channel sub-critical flow. J Civ Eng 34(2):91-101

6. Rezaei B (2006) Overbank flow in compound channels with prismatic and non-prismatic floodplains. Doctoral dissertation, University of Birmingham

7. Adel A, Akhtari AA, Dehghani AA (2016) Experimental and numerical investigation of the flow field in the gradual transition of rectangular to trapezoidal open channels. Eng Appl Comput Fluid Mech 10:273-283. https://doi.org/10.1080/19942 060.2016.1149102

8. Myers WRC (1978) Momentum transfer in a compound channel. J Hydraul Res 16(2):139-150

9. Rajaratnam N, Ahmadi R (1981) Hydraulics of channels with flood-plains. J Hydraul Res 19(1):43-60

10. Mohanty PK, Khatua KK (2014) Estimation of discharge and its distribution in compound channels. J Hydrodyn 26(1):144-154

11. Tang X (1999) Derivation of the wave speed-discharge relationship from cross section survey for use in approximate flood routing methods. Doctoral dissertation, University of Birmingham

12. Singh PK, Khatua KK (2018) Lateral dissemination of depthaveraged velocity, boundary shear stress and stage-discharge curves for compound channels. ISH J Hydraul Eng. https://doi. org/10.1080/09715010.2018.1549962

13. Jaganadha Rao MV, Lakshmana Rao NS, Seetharamiah K (1970) On the use of energy and momentum coefficients in hydraulic flow computations. J. Irrig Power CBIP 27(3):315-326

14. Streeter VL, Wylie EB, Bedford KW (1998) Fluid mechanics. McGraw-Hill, New York

15. Li D, Hager WH (1991) Correction coefficients for uniform channel flow. Can J Civ Eng 18(1):156-158
16. Robertson JA, Crowe CT (1998) Engineering fluid mechanics. J Fluid Mech 376:376

17. Chanson H (2004) Hydraulics of open channel flow. Elsevier, Oxford

18. Castro-Orgaz O, Lozano D, Mateos L (2010) Energy and momentum velocity coefficients for calibrating submerged sluice gates in irrigation canals. J Irrig Drain Eng 136(9):610-616

19. Das BS, Khatua KK (2018) Numerical method to compute water surface profile for converging compound channel. Arab J Sci Eng 43(10):5349-5364

20. Das BS, Khatua KK (2018) Flow resistance in a compound channel with diverging and converging floodplains. J Hydraul Eng 144(8):04018051

21. Kolupaila S (1956) Methods of determination of the kinetic energy factor. Port Eng Calcutta India 5(1):12-18

22. Blalock ME, Sturm TW (1983) Closure to "minimum specific energy in compound open channel" by Merritt E. Blalock and Terry W. Sturm (June, 1981). J Hydraul Eng 109(3):483-486

23. Basak BC, Alauddin M (2010) Efficiency of an expansive transition in an open channel subcritical flow. DUET J 1(1):27-32

24. Keshavarzi A, Valizadeh M, Ball J (2010) Experimental study of the effects of submerged dikes on the energy and momentum coefficients in compound channel. Engineering 2(11):855

25. Mohanty PK, Dash SS, Khatua KK, Patra KC (2012). Energy and momentum coefficients for wide compound channels. In: 6 th international conference on advances in fluid mechanics, split, Wessex Institute of Technology with the collaboration of the University of Split in Croatia. http://dspace.nitrkl.ac.in/dspace/ handle/2080/1756

26. Luo ECR (2012) Energy and momentum coefficients in straight symmetric compound-channel flows. Int J Hydraul Eng 1(3):15-20

27. Alkhatib IA (2013) Investigation of momentum and kinetic energy correction coefficients in asymmetric compound crosssection flumes. Turk J Eng Environ Sci 37(1):69-78. https://doi. org/10.3906/muh-1112-15

28. Kubrak E, Kubrak J, Kiczko A (2015) Experimental investigation of kinetic energy and momentum coefficients in regular channels with stiff and flexible elements simulating submerged vegetation. Acta Geophys 63(5):1405-1422

29. Parsaie A, Haghiabi AH (2016) Numerical modeling of effect of dead zones on concentration profile of pollution in rivers. Water Sci Technol Water Supply 17:825-834

30. Hamidifar H, Omid MH, Keshavarzi A (2016) Kinetic energy and momentum correction coefficients in straight compound channels with vegetated floodplain. J Hydrol 537:10-17

31. Babovic V (2005) Data mining in hydrology. Hydrol Process Int J 19(7):1511-1515. https://doi.org/10.1002/hyp.5862

32. Giustolisi O (2004) Using genetic programming to determine Chezy resistance coefficient in corrugated channels. J Hydroinform 6(3):157-173

33. Harris EL, Babovic V, Falconer RA (2003) Velocity predictions in compound channels with vegetated floodplains using genetic programming. Int J River Basin Manag 1(2):117-123

34. Babovic V, Keijzer M, Aguilera DR, Harrington J (2001) An evolutionary approach to knowledge induction: genetic programming in hydraulic engineering. In: Bridging the gap: meeting the world's water and environmental resources challenges, pp 1-10 
35. Meshgi A, Schmitter P, Chui TFM, Babovic V (2015) Development of a modular streamflow model to quantify runoff contributions from different land uses in tropical urban environments using genetic programming. J Hydrol 525:711-723

36. Meshgi A, Schmitter P, Babovic V, Chui TFM (2014) An empirical method for approximating stream baseflow time series using groundwater table fluctuations. J Hydrol 519:1031-1041

37. Naik B, Khatua KK, Wright N, Sleigh A, Singh P (2018) Numerical modeling of converging compound channel flow. ISH J Hydraul Eng 24(3):285-297

38. Azamathulla HM, Ahmad Z, Ghani AA (2013) An expert system for predicting Manning's roughness coefficient in open channels by using gene expression programming. Neural Comput Appl 23(5):1343-1349

39. Ferreira C, Gepsoft $U$ (2008) What is gene expression programming, 2002

40. Guven A, Gunal M (2008) Genetic programming approach for prediction of local scour downstream of hydraulic structures. J Irrig Drain Eng 134(2):241-249

41. Karbasi M, Azamathulla HM (2016) GEP to predict characteristics of a hydraulic jump over a rough bed. KSCE J Civ Eng 20(7):3006-3011

42. Pradhan A, Khatua KK (2017) Gene expression programming to predict Manning's $\mathrm{n}$ in meandering flows. Can J Civ Eng 45(4):304-313

43. Guven A, Aytek A (2009) New approach for stage-discharge relationship: gene-expression programming. J Hydrol Eng 14(8):812-820

44. Sattar AM (2013) Gene expression models for the prediction of longitudinal dispersion coefficients in transitional and turbulent pipe flow. J Pipeline Syst Eng Pract 5(1):04013011
45. Bhowmik NG (1979) Hydraulics of flow in the Kaskaskia River. Illinois State Water Survey, Champaign

46. Singh PK, Khatua KK, Banerjee S (2018) Flow resistance in straight gravel bed inbank flow with analytical solution for velocity and boundary shear distribution. ISH J Hydraul Eng. https://doi.org/10.1080/09715010.2018.1505561

47. Singh PK, Banerjee S, Naik B, Kumar A, Khatua KK (2018) Lateral distribution of depth average velocity \& boundary shear stress in a gravel bed open channel flow. ISH J Hydraul Eng. https:// doi.org/10.1080/09715010.2018.1505562

48. Banerjee S, Naik B, Singh P, Khatua KK (2018) Flow resistance in gravel bed open channel flows case: intense transport condition. ISH J Hydraul Eng. https://doi.org/10.1080/09715 010.2017.1422189

49. Naik B, Khatua KK, Padhi E, Singh $P$ (2018) Loss of energy in the converging compound open channels. Arab J Sci Eng 43(10):5119-5127

50. Singh PK (2017) A study of rating curve and flood routing using numerical method. Masters dissertation, National Institute of Technology Rourkela, India

Publisher's Note Springer Nature remains neutral with regard to jurisdictional claims in published maps and institutional affiliations. 